Article

\title{
An Extended Decomposed Theory of Planned Behaviour to Predict the Usage Intention of the Electric Car: A Multi-Group Comparison
}

\section{Ingrid Moons $^{\dagger}$ and Patrick De Pelsmacker ${ }^{\dagger} * *$}

Faculty of Applied Economics, University of Antwerp, Prinsstraat 13, 2000 Antwerpen, Belgium; E-Mail: Ingrid.moons@uantwerpen.be

$\dagger$ These authors contributed equally to this work.

* Author to whom correspondence should be addressed; E-Mail: Patrick.depelsmacker@uantwerpen.be; Tel.: +32-3-265-4022; Fax: +32-3-265-4080.

Academic Editor: Marc A. Rosen

Received: 10 February 2015 / Accepted: 12 May 2015 / Published: 20 May 2015

\begin{abstract}
An Extended Decomposed Theory of Planned Behaviour (DTPB) is developed that integrates emotions towards car driving and electric cars as well as car driving habits of the DTPB, and is empirically validated in a Belgian sample $(n=1023)$. Multi-group comparisons explore how the determinants of usage intention are different between groups of consumers differing in environmentally-friendly behaviour, environmental concern, innovativeness and personal values. Besides attitudes, media, perceived complexity, compatibility and relative advantage, emotions towards the electric car and reflective emotions towards car driving have a strong effect on usage intention. Car driving habits and perceived behavioural control (facilitators and constraints) do not substantially affect usage intention. Only people differing in personal values show a different motivational structure for a number of important drivers of usage intention.
\end{abstract}

Keywords: electric cars; new product adoption; decomposed theory of planned behaviour; emotions; habits; early and late adopters 


\section{Introduction}

An important contribution towards reaching a more sustainable future is improving our mobility system [1]. The biggest part of the energy used in transport comes from burning petrol products. One of the options to counter this trend of deploying the natural sources and polluting the air is the partial or complete shift to electric vehicles [2]. Different car brands, such as Tesla (2003), Reva (1994) and DIVA (2009), Nissan Leaf and Opel Ampera have developed fully electric car alternatives that are already for sale. However, what will make or break the successful introduction of electric mobility is consumer acceptance [3-5].

Several models of innovation adoption have been proposed. These models almost exclusively focus on conscious cognitive drivers of innovation adoption. However, there is an overwhelming evidence of the role of affective reactions in consumer decision making. Traditional innovation models have largely ignored the role of emotions [6-9], especially in case of high involvement decisions about complex products such as cars, notwithstanding the fact that emotions play an important role in these decisions [10-12]. Also, in the context of the adoption of new, innovative and environmentally products, such as hybrid or electric cars, the role of anticipated emotions is particularly eminent [13-15]. Emotions towards a complex innovative and eco-friendly product such as an electric car may play an important role as determinants of the intention to use it. However, the role of these emotions in this type of adoption decision process is under-researched [2]. Besides electric-car specific emotions, also more product-category related emotions can be relevant for decision making [8]. Car drivers who prefer prestigious, sporty or off-road cars are less likely to perceive an electric vehicle as an attractive substitute. On the other hand, people who feel bad about the negative environmental impact of their car use are more likely to see the benefits of changing to the electric vehicle [16]. Therefore, investigating the adoption process of electric vehicles should also take emotional responses towards car driving in general into account. Traditional innovation adoption models have also ignored the role of these product category-specific affective responses.

Past behaviour affects future behaviour [17-19]. The potential influence of habits on decision making is high [20]. Habits are the result of repeated pleasurable experiences in the same context. In general, it can be expected that positive emotions related to the habitual product experience of car driving will reinforce the habit and inhibit people to adopt a new travel mode, such as the electric car [21,22]. Habits, and more particularly their emotional antecedents, so far have not been taken into account in explaining the usage intention of innovations in a context in which they may play an important role, such as car buying and car use.

The processes that drive the usage intention of a new environmentally friendly or sustainable product may be different for different consumer segments [23]. In their study of the marketing of electric vehicles, Gärling and ThØgersen [16] argue that it is very important to correctly identify early adopters to find out to what extent their decision making process is different from late adoption intention groups. Because the introduction of the electric car is still in its infancy, insights into the motivations and barriers of electric car acceptance, especially by early adopter market segments, are important for a successful introduction of the electric car.

The present study tries to answer the following research questions: 
RQ1: What are the determinants of the usage intention of an electric car, and what is the role of emotions towards the electric car, car driving habits, and their emotional antecedents, next to traditional cognitive determinants of adoption intention?

RQ2: To what extent is the relative importance of these determinants different for possible early and late adopter consumer segments such as individuals with high and low environmental concern and behaviour, different degrees of innovativeness, and different value orientation?

The key theoretical contribution of the present study is that, for the first time, it tests a comprehensive model in which, besides traditional cognitive motivations of innovation adoption, also the relative importance of the emotional response towards the electric car, as well as the role of car driving habits and their emotional antecedents are considered, to predict the usage intention of an eco-friendly innovative consumer durable, i.e., the electric car. Additionally, the moderating role of various consumer characteristics on intention formation is investigated, i.e., differences in motivational processes across consumer segments that may differ in their intentions to use the electric car are systematically explored.

The results show that, for most consumer segments, emotions are the most important driver of electric car usage intention, followed by the attitude towards electric cars. Attitude, in turn, is determined by lack of complexity, compatibility and relative advantage of the electric car. The effect of most cognitive motivations to use the electric car are mediated by the emotions towards the electric car. Reflective emotions towards current car driving are significant drivers of usage intention. Neither habits nor constraints have a significant influence on usage intention. Although people that are highly environmentally concerned already demonstrate more environmentally-conscious behaviour, and innovative individuals pronounce stronger intentions to use the electric car, the process underlying this intention formation does not differ much from less environmentally committed and less innovative individuals.

The results of the present study provide designers, marketers of electric cars and public authorities with insights that should enable them to fine-tune their persuasive efforts in promoting electric vehicles. They should develop and position electric cars in such a way that it leads to positive attitudes, but most importantly, that they evoke positive emotional responses. They should emphasize that using an electric car is simple and compatible with what one is used to. Mass media campaigns should be considered as, at this point, they have a stronger impact on intention formation than peers. Marketers and public policy should stress the fact that driving an electric car is not basically different from using a traditional one, and that consumers do not have to change their habits when buying an electric model. The best chance to get the adoption process started is to persuade innovative individuals who are environmentally concerned, who already act in a more environmentally friendly way and stick to values such as adventure, hedonism, and benevolence.

\section{Conceptual Framework and Hypotheses}

\subsection{Decomposed Theory of Planned Behaviour}

One of the most influential and comprehensive theories for studying adoption processes is the Decomposed Theory of Planned Behaviour (DTPB) [24]. The DTPB decomposes the three main antecedents of behavioural intention of the Theory of Planned Behaviour (TPB) into a set of salient beliefs based on the Innovation Diffusion Theory and the Technology Acceptance Model. 
The TPB explains behavioural intentions and behaviour by means of three antecedents: The attitude towards the behaviour, the social influence on the behaviour (subjective norm) and perceived behavioural control in conducting the behaviour. Decision making is guided by a rational evaluation of behavioural consequences [25]. Attitudes towards the behaviour reflect the extent to which this behaviour is favourably or unfavourably evaluated. Social influence or the subjective norm is "the person's perception of the expectations of important others (reference groups) about a specific behaviour" [26] (p. 117). The effect of the subjective norm on behaviour intention is called the "compliance effect". Perceived behavioural control is "a person's perception of how easy or difficult it would be to carry out the behaviour" [26] (p. 119). This is affected by the perception of one's own skills but also by the eventual constraints or facilitators in the context of the decision [27-29]. In the case of electric cars, various control factors can be envisaged, for instance, an electric car has a limited range, charging the batteries at home in normal everyday sockets takes about eight hours, and public charging infrastructure is not yet set to point. The TPB has often been used for analysing environmentally related behaviours [30-33].

In the DTPB, the antecedents of the attitude towards the behaviour are the three most stable innovation characteristics defined by the innovation diffusion theory [34,35]: complexity, relative advantage and compatibility. Complexity is the degree to which an innovation is perceived as difficult to understand and use. Relative advantage is the degree to which an innovation is perceived as better than what already exists. Compatibility is the degree to which an innovation is perceived as being in line with existing values, past experiences, and needs of potential adopters. Originally, Rogers [34] posited that the decision to adopt or reject an innovation is affected by two more product attributes: Observability and triability. Observability is the degree to which the results of an innovation are visible. Triability is the degree to which one can experiment with an innovation. Observability and triability, though generally important in adoption processes, are not so relevant in the case of the electric car adoption, as it is still in its early introduction phase and almost not available on the market. Due to this lack of availability and the very limited number of electric cars on the road, triability by consumers is difficult to assess, and observability is extremely low.

The antecedents of attitude in the DTPB are also consistent with the Technology Acceptance Model (TAM) [36]. The TAM assumes that a person's attitude and behavioural intention towards using a new technology are influenced by the perceived usefulness and the perceived ease of use of the innovation [37,38]. Perceived usefulness is the degree to which an individual believes that using a particular technology will enhance his/her performance. Perceived ease of use is "the degree to which a person believes that using the product will be effortless" [36] (p. 320). Schepers and Wetzels' [38] meta-analysis of 53 studies showed that perceived usefulness ( $\mathrm{r}$ between 0.27 and 0.84 ) and perceived ease of use ( $\mathrm{r}$ between 0.05 and 0.73 ) are highly correlated with attitude in 15 of these studies. King and He's [37] meta-analysis of 88 TAM studies also showed that both perceived usefulness and perceived ease of use are relevant measures that can be used in a variety of contexts. In the DTPB, complexity is similar to perceived ease of use, and relative advantage is comparable to perceived usefulness $[35,39,40]$.

In the DTPB, the influence of the subjective norm is decomposed into two main reference groups, i.e., mass media and peers, the impact of which may be different [41,42]. Individuals choose to perform an action when important people in their life or influential reference groups such as media say they should comply. For instance, Griskevicius et al. [43] found that status motives influenced the desire for green 
products. For perceived behavioural control, Taylor and Todd [24] follow Ajzen's [44] conceptualization. Perceived behavioural control is decomposed into perceived personal ability and external source constraints and facilitators [45]. Perceived personal ability is based on Bandura's notion of self-efficacy [46]. Perceived self-efficacy is consumers' beliefs in their ability to influence events that affect their lives. Facilitators and constraints are similar to Triandis' [47] facilitating conditions and are defined in terms of resources (time, money) and technological possibilities (charging facilities, car maintenance).

The conceptual model is presented in Figure 1. In the traditional DTPB, the intention to use the electric car is determined by the attitude towards the electric car, the subjective norm and perceived behavioural control. Three antecedents of attitude are defined: Complexity, relative advantage and compatibility. Two different reference groups, i.e., peers and media, also determine usage intention. Perceived behavioural control is decomposed into perceived ability to perform the behaviour and the external source constraints and facilitators that inhibit or facilitate it. The DTPB predicts a positive effect of a favourable attitude on usage intention [48]. Perceived compatibility, relative advantage and lack of complexity are cognitive belief antecedents of this general attitude and should affect this attitude positively [49]. Peers and media are expected to have a positive effect on behavioural intention, due to the compliance effect [48]. Most studies also find a positive effect of perceived ability and a negative effect of constraints [24]. Hence, based on previous findings, we expect:

Hla: A positive attitude towards the electric car has a positive effect on the intention to use it.

H1b: A perceived positive subjective norm (peers and media) has a positive effect on the intention to use the electric car.

Hlc: The perception of being able to use the electric car (personal ability) has a positive effect on the intention to use it.

H1d: Perceived external constraints have a negative effect on the intention to use the electric car and perceived external facilitators have a positive effect on the intention to use the electric car.

H1e: Perceived compatibility, relative advantage and lack of complexity have a positive effect on the attitude towards the electric car.

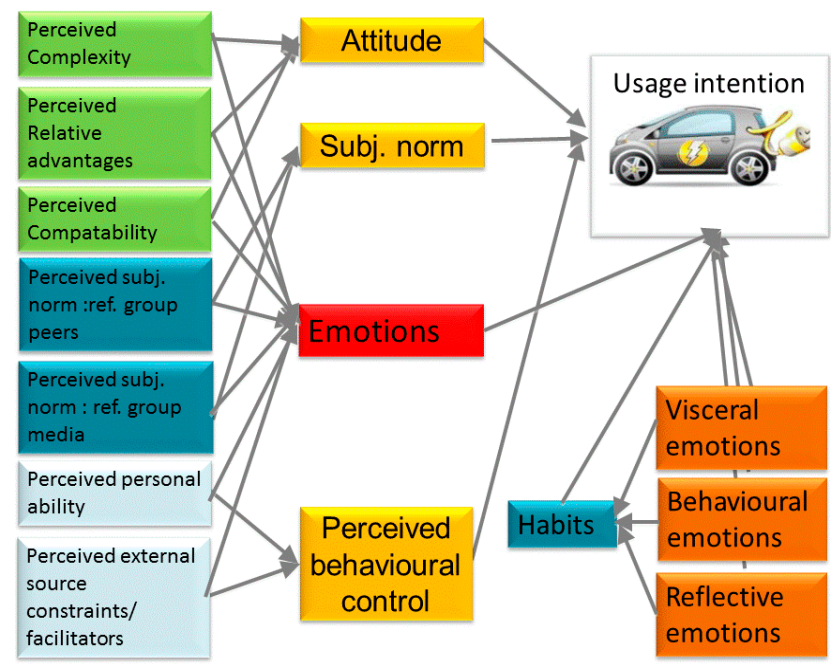

Figure 1. Extended Decomposed Theory of Planned Behaviour model. 


\subsection{Emotions towards the Electric Car in the Decomposed Theory of Planned Behaviour}

One of the purposes of this study is to extend the DTPB with emotional motivators that may also have an effect on the usage intention of electric cars. Emotions are valenced affective reactions to perceptions of situations $[8,9,50]$. Notwithstanding the overwhelming evidence of the role of affective reactions in consumer decision making, conceptual models such as the DTPB and empirical research on the adoption (intention) of innovations or (new) behaviour have largely ignored the role of emotions [6-9]. In the remainder of this study, we will use the term "emotions" to refer to affective responses to products or situations.

The Elaboration Likelihood Model (ELM) [51] posits that in high-involvement situations people would predominantly cognitively process stimuli or messages, while in low-involvement situations peripheral cues such as affective reactions to the stimulus would determine responses. However, emotions can also be a strong determinant of consumer behaviour in high involvement situations, such as buying a car. For instance, Pham [10] found that relevant and diagnostic emotions strongly determine behaviour. The Affect Infusion Model (AIM) posits that decision making in the course of substantive processing about complex stimuli made without the benefit of objective evidence, should show great affective effects [52]. Chaudhuri et al. [13] argue that the innovation literature has often overlooked emotions as a cause of successful diffusion. They argue that the role of emotions is particularly eminent in the context of new products that represent radical innovations. One of the examples they give is the adoption of hybrid cars. In line with this, Koller et al. [2] state that green consumption seems to be triggered by a complex pattern of both cognitive and affective elements. Many authors argue for integrating affective responses into extant adoption decision models [53-55].

Emotions have been added to cognitive decision models such as the Theory of Planned Behaviour for various products and issues, and have been found to be highly relevant for predicting behavioural intentions $[9,56,57]$. Various studies on the role of emotions in the TPB relate to issues or behaviours that are relatively highly involving [58]. Bae [58] found that emotions enhance the explanatory power of the TPB in predicting intentions to cornea donations. Hynie et al. [59] found that self-conscious emotions had a significant effect on condom use. Perugini and Bagozzi [60] established that anticipated emotions appeared to be highly significant in explaining body weight regulation and studying effort.

In the area of mobility decisions, for instance, Duran et al. [61] extended the TPB with emotional aspects to predict vehicle use. Emotional responses appeared to be more important to predict behaviour than, for instance, perceived behavioural control. Wood and Moreau [62] claim that emotional influences are the greatest during the early learning stages of product usage. They argue that the emotional (anticipation of) experience is more influential for technological or functional innovations (e.g., computer programs, GPS) than for simple experiential or aesthetic products. Also, Kwortnik and Ross [63] state that emotions are particularly important early in the decision process. The pleasure of consumption can begin before the act of consuming. Bagozzi [64] states that when measuring emotions towards a new product that is in its early stage of introduction, consumers cannot express their affective reactions in multidimensional terms, but only in general valenced feeling terms, and, in line with, e.g., Koller et al. [2], we measure the emotional response to using the electric car accordingly (see hereafter).

Most authors argue that emotional responses to a product are a direct driver of intentions [64] and therefore, an independent determinant of usage intentions. Emotions are a distinct construct from general 
attitude or affective attitude $[48,57]$. An attitude is an evaluative judgment of a stimulus that can contain both cognitive and affective elements [9,38]. Emotions are valenced affective reactions to emotion-eliciting objects/states [8,9]. Venkatesh et al. [48] claim that emotions can have a direct influence on behaviour that is not captured or summed up by attitude judgment. Cars are especially prone to elicit strong emotional feelings. "Green to feel good" [2] can be an important motivator to adopt the electric car. Therefore, we model emotional reactions to the electric car as an independent determinant of usage intentions alongside the traditional variables of the TPB model. We expect:

\section{H2: Positive emotions towards the electric car have a positive effect on the intention to use it.}

Cognitive responses and beliefs may impact the usage intention of the electric car in their own right. However, they may also generate negative or positive emotions that, in turn, inhibit or stimulate usage intention. In other words, emotions can significantly mediate the effect of cognitive considerations on usage intention. The affect-as-information theory [52] posits that, rather than forming a judgment on the basis of features of a target directly, individuals may ask themselves: "How do I feel about them?" and in doing so, may be guided by their feelings to judge the cognitive aspects of a stimulus. Also Koller $e t$ al. [2] state that rational cognitions about whether using a car might negatively affect the natural environment might have a significant impact on how the car is perceived in terms of emotional value (Figure 1). We expect:

H3: Emotions towards the electric car mediate the effect of perceived complexity, compatibility, relative advantage, the subjective norm (peers and media) and perceived behavioural control (personal ability, facilitators and constraints) on the intention to use it.

\subsection{Car Driving Emotions and Habits in the Decomposed Theory of Planned Behaviour}

Unlike reasoned decisions, habit is defined as an act resulting from repeated performances. A lot of research has found that past behaviour affects future behaviour [17,18,65]. Habits are cued by recurring stimuli in a stable context $[66,67]$. In the case of car driving, the daily returning situations of going to the store or to work can trigger people to take out the car [20]. Empirical research shows that extending the DTPB with variables that capture habits leads to a better prediction of travel mode choicethe adoption intention. In many studies, habitual car use has been found relevant [68-72].

People find it very difficult to inhibit tempting behaviours that provide immediate pleasure and convenience. Habits are the result of repeated pleasurable experiences and positive emotions. The importance of car driving affect in developing driving habits is recognized by Tengstrom [21] and Sandqvist [22]. Consumers that drive a car can be expected to have more specific emotional reactions to the car driving experience than to a novel electric car. Therefore, for the emotions towards car driving, we measure a number of specific emotions, based on Norman's conceptualization [73]: Visceral emotion, is perception-based and relates to visceral aspects that are related to product appearance. Behavioural emotion, is expectation-based and corresponds with behavioural aspects that have to do with the pleasure and effectiveness of use. Reflective emotion, is intellectually based and corresponds with reflective dimensions that are concerned with self-image, personal satisfaction and memories.

Two points of view are possible to model habits and current car driving emotions into the DTPB. Repetition of a behaviour and repeatedly using a product may lead to positive emotions associated with 
this product (use). However, we posit that the causal relation between car driving emotions and habits is the other way around. Reflective emotions towards car driving may make people more critical towards the (environmental) consequences of car driving, and may therefore have a positive effect on the intention to use the electric car that could alleviate these consequences. Strong positive visceral and behavioural emotions towards current car driving may lead people to disliking the electric car as a less satisfying alternative to their current vehicle. Positive visceral and behavioural emotions towards car driving may reinforce car driving habits, while negative reflective emotions with respect to the consequences of car driving may have a negative effect on car driving habits. In turn, it may be expected that the habit of current car use is inhibiting the intention to use another car system [73] (Figure 1). Hence, we expect:

H4a: Car driving habits has a negative effect on the intention to use the electric car.

H4b: Reflective emotions have a positive and visceral and behavioural emotions have a negative effect on electric car usage intention. These effects are mediated by car driving habits.

\section{Car Usage Intention Formation Process}

In their study of the marketing of electric vehicles, Gärling and ThØgersen [16] argue that it is important to correctly identify early adopters. Equally important as identifying these groups is to find out to what extent their decision making process is different from late adoption intention groups. Because the introduction of the electric car is still in its infancy it is interesting to find out who the early adopters for this product innovation are, and whether and how the adoption process differs between early and late adopters, in other words, how consumer characteristics moderate the motivational process of usage intention formation towards the electric car. In the present study, four individual difference constructs are explored that are expected to identify early and late adopter groups of environmentally-friendly new products: personal values, environmental concern, environmental behaviour, and innovativeness.

\subsection{Personal Values}

Values are beliefs that lead to desirable end states or behaviour. They transcend specific situations and they guide evaluations of behaviour. Personal value orientations have often been referred to as determinants of pro-environmental behaviour, such as recycling, donating items to reuse, and walking to conserve energy [74,75]. Schwartz [76] derived a typology of 10 values, distinguishing among the type of motivational goals they express: universalism, benevolence, conformity, tradition, security, power, achievement, hedonism, stimulation, and self-direction. Schwartz's [76] value types of "universalism' and 'benevolence' have been found to be positively related to pro-environmental attitudes and behaviour [77,78] while the "achievement" and "power value" types (power, achievement, stimulation, self-direction) have been shown to be negatively related to pro-environmental attitudes and behaviour [68,78-80]. Chua et al. [81] report that hybrid car buyers value social image factors more than the quality and appeal of the car: The car makes them look good, it makes them equal to family members, they own the same brand as my friends and family, etc. This is related to the value type "conformism". In view of previous findings that indicate the relevance of several dimensions of the Schwartz framework 
for pro-environmental behaviour and eco-innovation, this value framework is used as one of the moderators of motivational processes for adopting a pro-environmental innovation such as the electric car.

\subsection{Environmental Concern}

Environmental concern is the evaluative response towards environmental issues [82-84] and is assumed to be the underlying general attitude against environmental deterioration. Attitudes towards the environment or environmental values can be powerful predictors of consumers' actions to protect the environment. Bamberg [85] and Bamberg and Möser [86] showed that the degree of environmental concern can have a strong impact on people's behaviour in specific environmentally related domains such as recycling, energy savings, buying environmentally friendly products and travel mode choices. Gärling and Thøgersen [16] found that environment-friendliness is highly important for people in favour of electric cars. Oliver and Rosen [87], Heffner et al. [88] and Koller et al. [2] in their studies on hybrid vehicles state that environmental values have in previous research been very predictive of environmental behaviour. Similarly, Gallagher and Muehlegger [89] found that social preferences for environmental quality and energy security were a major determinant for consumer adoption of hybrid vehicles. Nilsson and Küller [90] found that environmental attitudes were more important than factual knowledge in promoting pro-environmental travel behaviour [91]. The significance of environmental attitude was also found in studies on green drivers' choice for hybrid cars [18]. Therefore, environmental concern is a potentially relevant moderator of the usage intention process of electric cars.

\subsection{Environmental Behaviour}

Consumers can be segmented based on different levels of environmental behaviour [92-94]. ThØgersen [95] demonstrates that environmentally friendly behaviours are not independent. When people start to act in an environmentally friendly way in one area, this behaviour tends to spill over into other areas. Consequently, environmental behaviour is a relevant moderating variable to study the usage intention process of electric cars.

\subsection{Innovativeness}

"Consumer innovativeness is the predisposition to buy new and different products and brands, rather than remain with the previous choices and consumption patterns" [96] (p. 56). Egbue and Long [97] state that trends in technology adoption suggest that, while new technology is intrinsically attractive to a few early adopters, the majority of consumers remain close-minded about a new technology. A small group has a positive attitude towards novelty and is likely to adopt new technologies [88]. Edison and Geissler [98] state that a lot of people are uncomfortable with technological changes and uncertainty that goes along with these changes, and therefore are unwilling to accept them. The majority chooses familiar and traditional products [99]. Innovativeness is the bottom-line type of behaviour in the diffusion process [34]. Therefore, in the context of an eco-innovation such as the electric car, the degree of innovativeness is a relevant moderator of the adoption process. 


\section{Empirical Study}

The extended DTPB model is tested and the moderating effect of consumer characteristics are investigated by means of a quantitative study in a sample of the Flemish-Belgian population. However, first a qualitative study was set up to further explore the relevance of the proposed extended DTPB and its components. This qualitative research also supports the operationalization of the variables in the model.

\subsection{Exploring the Extended DTPB Dimensions for Electric Car Use: A Qualitative Investigation}

\subsubsection{Procedure}

A group discussion was held on 2 April 2009 at the Amsterdam Motor show. Twelve respondents participated in this discussion, all of them highly involved in cars and mobility. All of them had a link with the automotive or mobility industry and had reported to be well informed about new trends in automotive. The group consisted of 10 male and 2 female respondents. All respondents had a driver's license and were between 25 and 50 years old.

First, the respondents discussed personal mobility and their current knowledge and expectations of electric cars. This took about $45 \mathrm{~min}$. They discussed their current car use among other travel modes, knowledge about the electric car, current image of the electric car, and perception of using the electric car. After the discussion, they were invited to visit part of the auto show. During this discovery walk, they were observed. The observation was carried out following a topic guide: facial expressions, spontaneous verbal reactions and body language were noted. The respondents were followed by three observers/interviewers as they walked along the guided tour of the auto show. The facial expressions were observed by three researchers that accompanied the walk through the roadshow. Although the observational output was qualitative and not guided by a formal measurement method, it was generally based on the operationalization of facial emotional expressions as proposed by Laurans et al. [100]. The respondents also received a questionnaire that helped them write down their impressions: first impression of the presented car, impression of the usability of the car, impression of the compatibility of the system with the way they organize their mobility, compatibility of the system with their values, eco-friendliness of the system, worries about the impact of the system, impression the car should make on their peers, impression of driving the car, impression of the environmentally friendliness. They were also shown a prototype of an electric car.

They saw a movie of a man driving the electric car to go to work. A lot of new opportunities of the car were presented in the movie. The participants also could take place in an electric car and they could pretend driving it through the streets of Amsterdam in front of a big real-life screen (simulation test). Furthermore, a team of designers was at their disposal to answer questions. Afterwards they got the opportunity to further discuss the electric car and its possibilities with students and lectors of a technical university. Finally, they saw various cars that were positioned as environmentally friendly, amongst which a hybrid car (Toyota Prius), an electric distribution van (DIVA), and a more futuristic car made of eco-friendly smart textiles. Afterwards, they went back to the discussion room and talked for one and a half hours about their experiences and expectations. This discussion was organized around the following topics: What are the motivators to drive an electric car? 
How is the attitude towards the electric car now? What underlies this attitude?

What are the constraints to driving an electric car?

How can driving an electric car be facilitated?

Does driving an electric car seem something they could manage easily?

Which reaction do they expect from family, neighbours and friends on electric car driving? How would these reactions influence them?

Did they notice information about the electric car in the media? Where? What did they remember? How does this affect their opinion?

\subsubsection{Results}

The exploratory study was intended to be a "reality check" of the relevance of the motivational variables included in the conceptual model. The study confirms our expectations on the importance of the concepts in the DTPB and of the additional "habits" and "emotions" factors. All the determinants of the adoption intention as proposed in the extended DTPB appear to be relevant to take into account in further empirical research. Respondents made it clear that they did not always make a conscious travel mode choice, but that many of their travel decisions were habitual. The exposure to and simulated experience with the electric car revealed that, besides the cognitive components of the framework, emotional experience was very important. Facial expressions and body language revealed strong emotional responses to electric cars, confirming our conceptualization that emotions are relevant and important responses when confronted with an electric car. Emotions were measured directly by observing facial expressions and body language and spontaneous verbal outings during the guided tour of the auto show. In the discussion afterwards, the reason for these expressions was asked for. Three types of car driving emotional reactions were indeed observed. Visceral emotions were mostly observed when the respondents were confronted with prototypes of the car. Behavioural emotions were apparent during the simulation test. Reflective emotions were more verbally expressed during the whole observation exercise and during the discussion sessions. The qualitative exploratory study confirms the relevance of the decomposed theory of planned behaviour and its extensions (emotions and habits). The information gathered in this exploratory stage was also used as input for further operationalization of the scales in the main quantitative study.

\subsection{Quantitative Study: Data Collection Procedure, Measures and Analyses}

\subsubsection{Data Collection Procedure}

In March 2012, an online survey was conducted in a sample of 1023 respondents between 18 and 65 years old that hold a driver's license, and were representative of the Flemish speaking Belgian population in terms of gender, age and level of education. Respondents received a link containing the questionnaire in which the constructs of the extended DTPB and the moderating variables discussed above were measured. $50.4 \%$ of the sample was male, $16.6 \%$ between 18 and $25,42.3 \%$ between 26 and 45, and $41.1 \%$ older than $45.58 .7 \%$ has a high school diploma, and $41.3 \%$ a higher education one. Respondents were invited to participate by means of the following introduction. "We are conducting $a$ survey concerning car driving and car driving behaviour. Thank you for your participation. You should answer each question according to your own opinion. There are no good or bad answers. Your responses will be analysed statistically and anonymously". 


\subsubsection{Measures}

The measures for the constructs in the extended DTPB are (modifications of) existing five-point Likert scales used in earlier comparable research settings [24,101,102], or are (partly) based on the exploratory qualitative research. The original scales were as follows. Electric car usage intention (INT) was measured by means of a three-item five-category Likert scale [101]. The attitude towards the electric car (ATT) was measured by means of a scale that was the sum of positive choices made on six dichotomous items: good-bad, like-don't like, clever-stupid, nice-not nice, useful-useless, suitable-non-suitable [101]. Compatibility (COMP), relative advantage (RelAdv) and complexity (COMPL) were measured by means of 5-item, 8-item and 4-item 5-category Likert scales, respectively [34,36,101]. Subjective norm peers (SNP) and subjective norm media (SNM) were measured by means of 7-item and 3-item 5-category Likert scales, respectively [102-104]. External facilitators and constraints (perceived behavioural control-PBC/ESC) were measured by means of a 10-item 5-category Likert scale, developed on the basis of the qualitative study. Personal ability (PBC/PA) was measured with a 4-item 5-category Likert scale [101]. Emotions towards the electric car (EEC) was measured with a 3-item 5-category Likert scale $[9,101]$. Emotions towards car driving (ECC/Visc, ECC/Beh and ECC/Ref) were measured with a 17-item 5-category Likert scale: "To what extent do the following aspects contribute to you experiencing positive emotions when driving a car: $1=$ not at all-5 = a lot", based on the qualitative study and [73]. Finally, car driving habits (HABITS) were measured by means of a 6-item 5-category Likert scale [102-104].

\subsubsection{Measurement Model}

Based on the scales for the various constructs in the proposed model, a measurement model was first developed to guide model specification $[105,106]$. First, an exploratory principal components analysis followed by a Cronbach alpha analysis was carried out per construct. For most constructs, all the original items loaded on one single factor and produced alphas of well above 0.70 . For some other constructs, all items loaded on one factor, but some items had to be removed to obtain a good internal consistency of alpha $>0.70$.

The items measuring the external source constraints and facilitators did not produce a useful factor structure. Based on the results of the qualitative study and on previous literature, it was therefore decided to include the most relevant single-item PBC measures in the model. These items were: My budget is sufficient to buy an electric car (ESC1), Cars with a combustion engine will soon not be allowed to enter the city (ESC2), You can drive a long distance with an electric car (ESC3), Not everyone can charge an electric car at home(ESC4), Maintaining the electric car is well organized. (ESC5), I will not be allowed to charge my electric car with energy I have produced myself (ESC6), the battery of an electric car cannot be charged on the road (ESC7).

Principal component analysis reveals that the 17 emotional reactions toward car driving can be interpreted as representing the three process levels proposed by Norman [73]. They are defined by the following reduced item set: Visceral emotions: Throb of the engine, rapid acceleration, information on the dashboard, the beauty of the interior, the looks of the car, high speed possibility (Alpha: 0.884); Behavioural emotions: Enjoying the environment while driving, getting relaxed while driving (Alpha: 0.742); 
and Reflective emotions: Low cost of the car, environmentally friendly car, economic fuel consumption of the car (Alpha: 0.861).

Subsequently, the constructs and items were used as input in a confirmatory factor analysis to test the measurement model, using SPSS AMOS 19. Based on modification indexes and item loadings, the scales were further refined. In order to get an acceptable measurement model fit, some items were removed. Only the items with a Critical Ratio (C.R.) $>|1.96|$ and a Standardised Regression Weight (SRW) of above 0.50 were kept in the model. All SRWs were well above these cut-off points, except for one item of the visceral emotions scale $(\mathrm{SRW}=0.41)$. The items for each construct that were retained after optimizing the measurement model, and that were used further in the empirical study, are shown in Table 1. Means and standard deviations of each construct are based on means across the items defining that construct. In the Structural Equation Model (see hereafter), all constructs are latent, except for "attitude" and the single-item PBC measures.

The measurement model possesses convergent validity, reliability and discriminant validity. All but one loadings of the items were higher than the recommended cut-off value of 0.50 , illustrating convergent validity. In addition, the average variance extracted (AVE) of all latent constructs was larger than the recommended cut-off value of 0.50 [107], ranging from 0.53 to 0.80 , except for visceral emotions (0.35). As to the latter, it was decided to keep it in the model in line with the conceptual structure and the results of the principal components analysis. Moreover, alpha (0.884) and composite reliability (0.73) of ECC/Visc are sufficiently high. All Cronbach alphas exceed the threshold of 0.70 (between 0.742 and 0.941 ), implying a satisfactory level of reliability. Also the composite reliabilities, with values between 0.73 and 0.97 , give a fulfilling indication of the reliability and one-dimensionality of the scales [107] (Table 2). All correlations between independent latent constructs are lower than 0.60, except for the correlation between SNM and compatibility (0.658) and compatibility and-complexity (0.759). All correlations between the latent constructs are significantly different from one, which indicates discriminant validity. The final scales and items used for model estimation are shown in Table 1.

Table 1. Descriptive statistics of constructs and items used in the final model.

\begin{tabular}{|c|c|c|c|}
\hline Constructs and Items & & Std. dev. & Alpha \\
\hline \multicolumn{4}{|l|}{ Usage Intention: Intention to use electric car } \\
\hline \multicolumn{4}{|l|}{ I have the intention to drive an electric car in the near future } \\
\hline I will recommend the use of the electric car to other people & \multirow[t]{2}{*}{ Mean: 2.551} & \multirow[t]{2}{*}{1.104} & \multirow[t]{2}{*}{0.921} \\
\hline I expect that I will be driving an electric car in the near future & & & \\
\hline \multicolumn{4}{|l|}{ Att: Attitude towards electric car } \\
\hline \multicolumn{4}{|l|}{$2=\operatorname{good}-1=$ bad } \\
\hline \multicolumn{4}{|l|}{$2=$ like $-1=$ don't like } \\
\hline \multicolumn{4}{|l|}{$2=$ clever $-1=$ stupid } \\
\hline \multicolumn{4}{|l|}{$2=$ nice $-1=$ not nice } \\
\hline \multicolumn{4}{|l|}{$2=$ useful $-1=$ useless } \\
\hline \multicolumn{4}{|l|}{$2=$ suitable $-1=$ not suitable } \\
\hline \multicolumn{4}{|l|}{ Comp: Compatibility } \\
\hline \multicolumn{4}{|l|}{ Driving an electric car suits to my way of life. } \\
\hline Driving an electric car suits to what I need. & Mean: 2.790 & 0.971 & 0.941 \\
\hline The electric car suits to the way I want to get organized. & & & \\
\hline
\end{tabular}


Table 1. Cont.

\begin{tabular}{|c|c|c|c|}
\hline Constructs and Items & & Std. dev. & Alpha \\
\hline \multicolumn{4}{|l|}{ RelAdv: Relative advantage. } \\
\hline $\begin{array}{l}\text { An electric car offers more advantages to our society than a car with a combustion engine. } \\
\text { Driving an electric car will be better to attain environmental norms, than driving a } \\
\text { car with a combustion engine }\end{array}$ & Mean: 3.702 & 0.892 & 0.823 \\
\hline \multicolumn{4}{|l|}{ An electric car will be less harmful to our planet than a car with a combustion engine } \\
\hline \multicolumn{4}{|l|}{ Compl: Complexity } \\
\hline \multicolumn{4}{|l|}{ It will be easy for me to drive an electric car } \\
\hline \multicolumn{4}{|l|}{ I can handle the electric car in a flexible way. } \\
\hline \multicolumn{4}{|l|}{ SNP: Subjective norm peers } \\
\hline $\begin{array}{l}\text { People who are important to me will support me when I should drive an electric car } \\
\text { People who are important to me try to convince me to drive an electric car }\end{array}$ & Mean: 2.330 & 0.572 & 0.885 \\
\hline \multicolumn{4}{|l|}{ SNM: Subjective norm media } \\
\hline $\begin{array}{l}\text { The media gave me a good feeling about using an electric car } \\
\text { Articles in the media influenced me to use an electric car }\end{array}$ & Mean: 2.637 & 0.911 & 0.773 \\
\hline Perceived behavioural control: External constraints and facilitators & Separate items & & \\
\hline ESC1: My budget is sufficient to buy an electric car & 2.301 & 1.215 & \\
\hline ESC2: Cars with a combustion engine will soon not be allowed to enter the city & 3.144 & 1.054 & \\
\hline ESC3: You can drive a long distance with an electric car & 2.042 & 0.980 & \\
\hline ESC4: Not everyone can charge an electric car at home & 3.261 & 1.151 & \\
\hline ESC5: Maintaining the electric car is well organized. & 2.713 & 0.779 & \\
\hline ESC6: I will not be allowed to charge my electric car with energy I have produced myself & 2.911 & 1.010 & \\
\hline ESC7: The battery of an electric car can't be charged underway & 2.712 & 1.073 & \\
\hline \multicolumn{4}{|l|}{ PBCPA: Perceived Behavioural Control: Personal ability } \\
\hline $\begin{array}{l}\text { I will have the knowledge and the capacity to drive an electric car } \\
\text { I am capable to drive an electric car } \\
\text { It is easy for me to control all things relevant for driving an electric car. }\end{array}$ & Mean: 3.817 & 0.756 & 0.873 \\
\hline \multicolumn{4}{|l|}{ EEC: Emotion towards the electric car } \\
\hline $\begin{array}{l}\text { I will like driving an electric car } \\
\text { I look forward to drive an electric car } \\
\text { Driving an electric car could frustrate me (r) }\end{array}$ & Mean: 3.131 & 0.916 & 0.825 \\
\hline \multicolumn{4}{|l|}{ Visc: Visceral Emotions towards car driving } \\
\hline $\begin{array}{l}\text { Throb of the engine } \\
\text { Rapid acceleration } \\
\text { Information on the dashboard }\end{array}$ & & & \\
\hline $\begin{array}{l}\text { Beauty of the interior } \\
\text { Looks of the car } \\
\text { High speed possibility } \\
\text { Technological sophistication }\end{array}$ & Mean:2.968 & 0.761 & 0.884 \\
\hline \multicolumn{4}{|l|}{ Behav: Behavioural Emotions towards car driving } \\
\hline $\begin{array}{l}\text { Enjoying the environment while driving } \\
\text { Getting relaxed while driving }\end{array}$ & Mean: 3.670 & 0.855 & 0.742 \\
\hline
\end{tabular}


Table 1. Cont.

\begin{tabular}{lcc}
\hline Constructs and Items & Std. dev. & Alpha \\
\hline Reflec: Reflective Emotions towards car driving & & \\
\hline Environmentally friendly car & Mean: 3.374 & 0.916 \\
Low cost of the car & 0.861 \\
Economic fuel consumption of the car & \\
\hline Habits & Mean: 3.050 & 1.104 \\
\hline Not using the car is something I would feel uncomfortable with & 0.923 \\
Using the car is something I do automatically & \\
Using the car is something I do without thinking about it. & \\
Using the car is one of my habits & \\
Using the car is typically me & \\
I don't have to think about using the car & \\
\hline
\end{tabular}

Table 2. Reliability and validity indices of model constructs.

\begin{tabular}{cccc}
\hline Variable & Alpha & Composite Reliability & Average Variance Extracted \\
\hline Usage intention & 0.921 & 0.83 & 0.62 \\
Habits & 0.923 & 0.92 & 0.66 \\
Visc & 0.884 & 0.73 & 0.35 \\
Behav & 0.742 & 0.77 & 0.63 \\
Reflec & 0.861 & 0.94 & 0.53 \\
EEC & 0.825 & 0.84 & 0.65 \\
SNM & 0.773 & 0.88 & 0.80 \\
SNP & 0.885 & 0.78 & 0.64 \\
PBCPA & 0.873 & 0.88 & 0.71 \\
Comp & 0.941 & 0.88 & 0.71 \\
RelAdv & 0.823 & 0.97 & 0.92 \\
Compl & 0.833 & 0.84 & 0.64 \\
\hline
\end{tabular}

\subsubsection{Measures for the Moderating Variables}

Additionally, the moderating variables were measured. These measures are not used in the model that tries to explain the underlying motives in adopting the electric car. They are used for multi-group comparisons. Schwartz' [76] short value (10 items) scale was used to measure personal values, i.e., to what extent respondents found each of the 10 value orientations important [108]:

(1). Achievement: To have success, be competent, ambitious, have influence on people and events.

(2). Power: Obtaining social status, the achievement of prestige, control or dominating others.

(3). Security: National security, security for the family, order in society, reciprocate favours.

(4). Tradition: Respect for tradition, humbleness, accept life, moderation.

(5). Conformity: Obedience, respect for parents and elder people, self-discipline, politeness.

(6). Benevolence: To be helpful, honest, forgiving, loyalty to friends, responsible.

(7). Universalism: To be broad-minded, loving a world full of beauty, social justice, peace, equality, wisdom, unity with nature, care for nature and the environment.

(8). Self-direction: Creativity, curiosity, freedom to choose your own goals. 
(9). Stimulation: Excitement, novelty, and challenge in life.

(10). Hedonism: To enjoy life, self-indulgence, fun.

This importance was measured by means of 5-point Likert scales. A principal components analysis revealed four relevant factors, representing $73.5 \%$ of the variance. In Table 3, these four factors are shown, as well as the value orientations (items of the measurement scale) loading on each factor, the mean and standard deviation, and the Cronbach Alpha per component. These components are defined as: (1) Conservatism: Security, tradition, conformity, (2) Self-oriented adventure: Self-direction, stimulation, hedonism, (3) Power: Achievement, power, and (4) Caring: Benevolence, universalism. The scores on the items loading on each factor were averaged. The mean scores of the four components were used in a K-means cluster analysis. Three clusters were retained based on the meaningfulness and coherence of their characteristics. The average scores of each component per cluster are shown in Table 4. The three clusters are significantly different in terms of the value components. The clusters can be labelled as: (1) The adventurous hedonist (CL1, 35.6\%), (2) The powerless benevolent (CL2, 41.6\%), and (3) The disconnected nonconformist (CL3, 22.9\%). Cluster 1 scores higher than the other two clusters on self-oriented adventure and power; cluster 2 scores very low on power, and cluster 3 scores relatively low on conservatism and caring. Each cluster was used as a separate group in the multi-group analysis (see hereafter).

Table 3. Value orientation components.

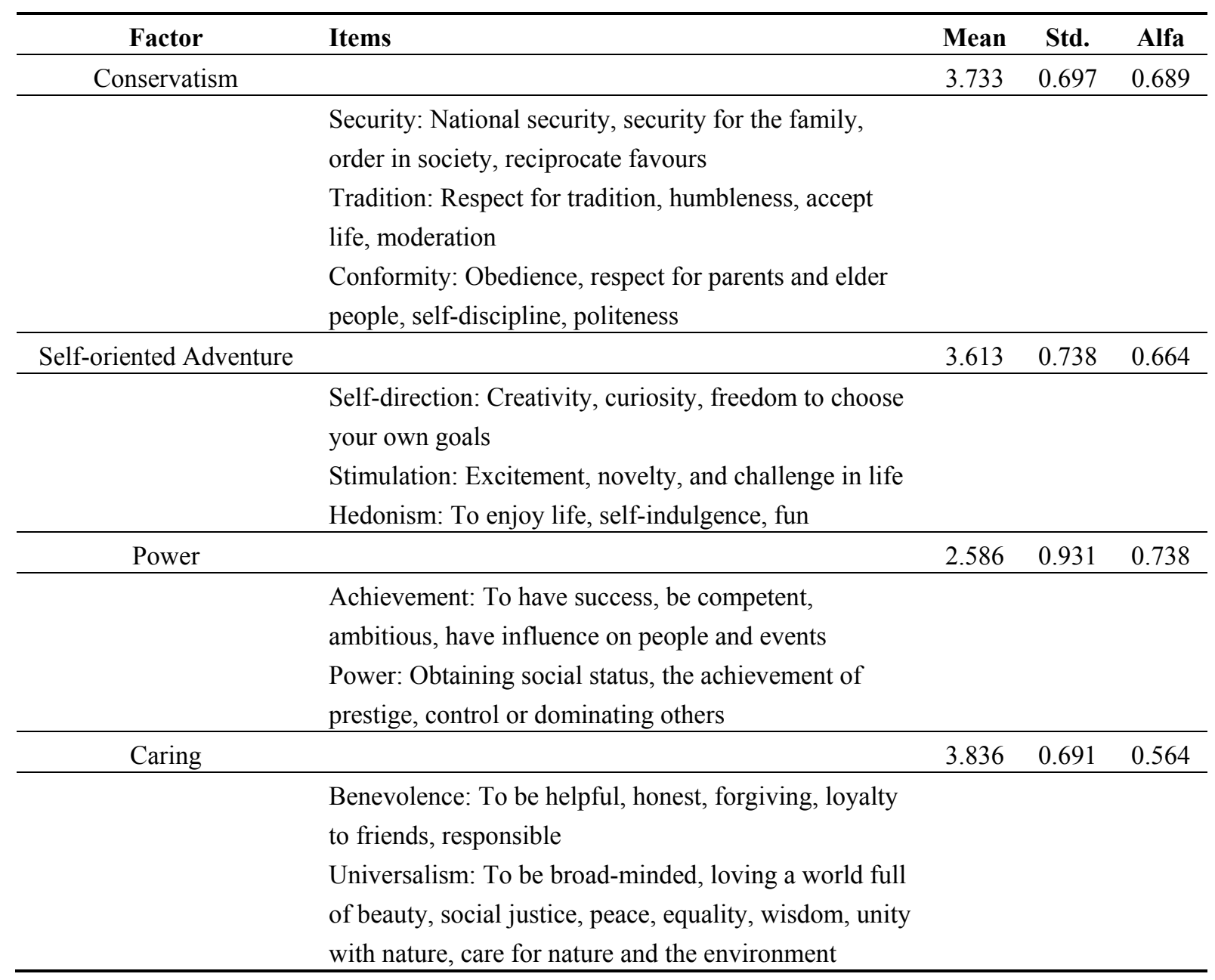


Table 4. Mean component scores per value type cluster.

\begin{tabular}{|c|c|c|c|c|}
\hline & & Cluster & & Sign \\
\hline & $\begin{array}{l}\text { Adventurous hedonist } \\
\text { (1) }(n=364)\end{array}$ & $\begin{array}{l}\text { Powerless benevolent } \\
\text { (2) }(n=425)\end{array}$ & $\begin{array}{l}\text { Disconnected nonconformist } \\
\text { (3) }(n=234)\end{array}$ & \\
\hline Conservatism & 3.94 & 3.91 & 3.10 & $<0.001$ \\
\hline Self-oriented adventure & 4.03 & 3.46 & 3.24 & $<0.001$ \\
\hline Power & 3.31 & 1.73 & 3.02 & $<0.001$ \\
\hline Caring & 4.0 & 4.07 & 3.15 & $<0.001$ \\
\hline
\end{tabular}

To measure environmental concern, the New Environmental Paradigm (NEP) Scale was used [109]. Respondents were asked to indicate the strength of their agreement or disagreement with each statement on a 5-point Likert scale:

(1). We are approaching the limit of the number of people the Earth can support.

(2). Humans have the right to modify the natural environment to suit their needs.

(3). When humans interfere with nature it often produces disastrous consequences.

(4). Human ingenuity will insure that we do not make the Earth unliveable.

(5). Humans are seriously abusing the environment.

(6). The Earth has plenty of natural resources if we just learn how to develop them.

(7). Plants and animals have as much right as humans to exist.

(8). The balance of nature is strong enough to cope with the impacts of modern industrial nations.

(9). Despite our special abilities, humans are still subject to the laws of nature.

(10). The so-called "ecological crisis" facing humankind has been greatly exaggerated.

(11). The Earth is like a spaceship with very limited room and resources.

(12). Humans were meant to rule over the rest of nature.

(13). The balance of nature is very delicate and easily upset.

(14). Humans will eventually learn enough about how nature works to be able to control it.

(15). If things continue on their present course, we will soon experience a major ecological catastrophe.

In a principal components analysis, all items load on one factor. The Alpha of the scale is 0.832 . Therefore, an average score across all 15 items was calculated to be used in further analysis. This average score was median split to obtain two groups (the median scorers were discarded), one low $(n=474)$ and one high (549) in environmental concern. The average environmental concern score is 3.644 (standard deviation: 0.535$)$.

The environmental behaviour measure used in the present study is a list of 15 possible environmental friendly behaviours one can act upon (based on [110] and on the qualitative study). Respondents had the choice between three answers for every possible behaviour item: "No, I don't do this"; "Yes, I do this for environmental reasons"; and "Yes, I do this for reasons other than environmental". The behaviours in the list relate to various domains. These behaviours were:

(1). I replaced most of my bulbs by energy saving bulbs

(2). I consistently sort my waste

(3). I normally buy biological soap (washing, dish washing, personal care)

(4). I invested in solar panels 
(5). I'm a member of an environmentally activist organisation

(6). I use rainwater and well water

(7). My energy is delivered by a green energy supplier

(8). When I go to the supermarket I avoid useless packaging

(9). I always take a quick shower in order not to waste too much water

(10). I installed a low flush toilet

(11). I often talk with others about a more environmentally friendly way of living

(12). My clothes are made environmentally friendly

(13). My house is extra isolated

(14). We installed a heat pump

(15). Whenever possible I don't use the car

The measure used in the analysis is the sum of the number of behaviours one conducts with the intention to act environmentally friendly. The average score is 3.468 (standard deviation: 3.064). These scores were median split to obtain two groups of high $(n=531)$ and low $(n=492)$ environmental behaviour (median scorers discarded).

The measure for innovativeness is inspired by Roehrich's [111] scale. Four items were added to capture the more cognitive and sensory dimension of innovativeness [112]. Ten 5-point Likert items anchored from totally disagree to totally agree were used, all loading on one factor (Alpha 0.903):

(1). I like to have new experiences and changes in my daily routine.

(2). I'm constantly looking for new ideas and experiences.

(3). I like variation and new things in my daily life.

(4). When getting bored, I look out for new challenges and experiences.

(5). I am more interested in buying new than known products.

(6). I like to buy new and different products.

(7). New products excite me.

(8). I am usually among the first to try new products.

(9). I know more than others on latest products.

(10). I try new products before my friends and neighbours.

The average score across the items was median split to obtain two groups (median scorers excluded) on high $(n=555)$ and low $(n=468)$ innovativeness. The overall mean score is 2.963 (standard deviation: $0.705)$.

\section{Results}

\subsection{Motivational Determinants of Electric Car Usage Intention}

To test the hypotheses, the model shown in Figure 1 was estimated by means of structural equation modelling (AMOS 19), using the items and constructs derived previously. The model fits the data well. Although $\mathrm{Chi}^{2} / \mathrm{df}$ (3.66) is above the recommended maximum of 3, the other indexes indicate a good model fit. CFI (0.91) and TLI (0.90) are on or above the recommended 0.90 cut-off, and RMSEA (0.05) is not higher than the recommended 0.05 cut-off [113]. 
Table 5 shows the Standardized regression Weights (SRW) of the causal paths between the constructs, and their levels of significance. A positive attitude towards the electric car has a significantly positive effect on usage intention, confirming H1a. The effect of subjective norms peers on usage intention is marginally significantly positive, whereas the media influence is of greater significance. This support H1b. The perception of one's own ability to drive an electric car has no significant effect on the usage intention. H1c is not supported. The only three external facilitators that have a (moderately) significant effect on usage intention are the idea of having enough budget to afford the electric car, the perception that you can drive a long distance with an electric car $(+)$ and the fact that the battery of the car cannot be charged while one is on the road (-). External constraints and facilitators apparently only play a marginal direct role in developing usage intention. H1d is only very partially supported.

Consistent with $\mathrm{H} 1 \mathrm{e}$, perceived compatibility and relative advantage and the perceived lack of complexity have a significant positive effect on the attitude towards the electric car. In support of H2, emotions towards the electric car are an important and highly significant predictor of usage intention.

Table 5. Standard regression weights and their levels of significance of the constructs in the model.

\begin{tabular}{|c|c|c|c|c|}
\hline Construct & & Construct & B & $\mathbf{P}$ \\
\hline \multirow[t]{16}{*}{ Usage Intention } & $\leftarrow$ & ATT & 0.189 & $<0.001$ \\
\hline & $\leftarrow$ & SNP & 0.066 & 0.054 \\
\hline & $\leftarrow$ & SNM & 0.148 & 0.002 \\
\hline & $\leftarrow$ & РBCPA & -0.002 & 0.939 \\
\hline & $\leftarrow$ & ESC1 & 0.066 & 0.007 \\
\hline & $\leftarrow$ & $\mathrm{ESC} 2$ & 0.031 & 0.225 \\
\hline & $\leftarrow$ & $\mathrm{ESC} 3$ & 0.050 & 0.057 \\
\hline & $\leftarrow$ & $\mathrm{ESC} 4$ & -0.010 & 0.668 \\
\hline & $\leftarrow$ & ESC5 & -0.039 & 0.125 \\
\hline & $\leftarrow$ & ESC6 & -0.020 & 0.413 \\
\hline & $\leftarrow$ & ESC7 & -0.040 & 0.091 \\
\hline & $\leftarrow$ & EEC & 0.453 & $<0.001$ \\
\hline & $\leftarrow$ & VISC & 0.040 & 0.198 \\
\hline & $\leftarrow$ & REFLEC & 0.106 & 0.002 \\
\hline & $\leftarrow$ & BEHAV & 0.020 & 0.517 \\
\hline & $\leftarrow$ & HABITS & -0.005 & 0.847 \\
\hline \multirow[t]{13}{*}{ EEC } & $\leftarrow$ & RelAdv & 0.084 & 0.003 \\
\hline & $\leftarrow$ & Comp & 0.496 & $<0.001$ \\
\hline & $\leftarrow$ & Compl & 0.225 & $<0.001$ \\
\hline & $\leftarrow$ & SNP & -0.034 & 0.224 \\
\hline & $\leftarrow$ & SNM & 0.144 & $<0.001$ \\
\hline & $\leftarrow$ & РBCPA & 0.112 & $<0.001$ \\
\hline & $\leftarrow$ & $\mathrm{ESC} 1$ & -0.031 & 0.122 \\
\hline & $\leftarrow$ & $\mathrm{ESC} 2$ & 0.042 & 0.046 \\
\hline & $\leftarrow$ & ESC3 & 0.009 & 0.689 \\
\hline & $\leftarrow$ & ESC4 & -0.043 & 0.030 \\
\hline & $\leftarrow$ & ESC5 & -0.027 & 0.212 \\
\hline & $\leftarrow$ & ESC6 & 0.011 & 0.570 \\
\hline & $\leftarrow$ & ESC7 & -0.022 & 0.265 \\
\hline
\end{tabular}


Table 5. Cont.

\begin{tabular}{ccccc}
\hline Construct & & Construct & B & P \\
\hline ATT & $\leftarrow$ & COMPL & 0.367 & $<0.001$ \\
& $\leftarrow$ & RELADV & 0.276 & $<0.001$ \\
& $\leftarrow$ & COMP & 0.241 & $<0.001$ \\
HABITS & $\leftarrow$ & VISC & 0.225 & $<0.001$ \\
& $\leftarrow$ & REFL & -0.262 & $<0.001$ \\
& $\leftarrow$ & BEHAV & 0.124 & 0.002 \\
\hline
\end{tabular}

Perceived relative advantage, compatibility and lack of complexity, and the media social norm all have a positive influence on the emotions towards the electric car. This is not the case for the influence of relevant others (peers). The perception of one's personal ability to drive an electric car has a significant positive influence on the emotions towards it. The concern about the fact that it is not possible for everyone to charge their car at home has a significant negative effect on the emotions towards the electric car and the fact that a car with a combustion engine would no longer be allowed to enter the city has a significantly positive effect. As expected, the effect of perceived relative advantage, compatibility and lack of complexity and of media subjective norm on usage intention are all partially mediated by the emotions towards the electric car. The effect of personal ability on usage intention is also fully mediated by emotions. These mediation effects are all confirmed by Sobel tests (all $p<0.001$ ) [114]. Contrary to expectations, the influence of peers only has a direct, non-mediated effect on usage intention. The effect of some of the external facilitators and constraints are significantly mediated by emotions, but their effect is very small. H3 is thus largely supported, except for the effect of external facilitators and constraints and subjective norm peers.

Contrary to expectations, car driving habits have no inhibiting effect on the usage intention of an electric car. H4a is not supported. However, the emotions towards car driving have the expected effect on habits: Visceral and behavioural emotions have a positive effect, and reflective emotions a negative one. Reflective emotions towards current car driving have a direct positive effect on electric car usage intention. However, car driving habits do not mediate the effect of emotions towards car driving on usage intention. Only reflective emotions towards car driving have a direct effect on usage intention. H4b is not supported.

\subsection{Differences in Motivational Determinants of Electric Car Usage Intention across}

\section{Consumer Segments}

In this part of the empirical analysis, the motivational process is compared of different consumer groups potentially representing early and late adopters of sustainable innovations. The structural equation model in Figure 1 was estimated for subsamples of respondents by means of multi-group analyses using SPSS AMOS 19, thus using consumer characteristics as moderators of the motivational process depicted in Figure 1. As outlined before, for the moderating variables environmental concern, environmental behaviour and innovativeness, the sample was median-split and the lowest scoring respondents and the highest scoring ones were compared. For the moderating variable value orientation, the three clusters were compared two by two. 
The usage intention scores per segment are reported in Table 6. All mean scores on usage intention are relatively low. This intention is significantly different between the third value cluster and the other two clusters. The disconnected nonconformist is less willing to use the electric car than the adventurous hedonist and the powerless benevolent. Highly environmentally concerned people pronounce a significantly stronger intention to adopt the electric car than lowly environmentally concerned individuals. People who do not generally act in an environmentally friendly way report a lower usage intention of the electric car than people that do act a lot in favour of the environment. Innovative people are significantly more likely to adopt the electric car than people that are less innovative.

Table 6. Differences in usage intention across segments.

\begin{tabular}{lccc}
\hline \multicolumn{1}{c}{ Usage Intention } & Mean Scores & Mean Scores & t-test \\
\hline Value clusters 1/2 & 2.6264 (value 1) & 2.629 (value 2) & $p=0.974$ \\
Value cluster 1/3 & 2.6264 (value 1) & 2.2934 (value 3) & $p<0.001$ \\
Value cluster 2/3 & 2.629 (value 2) & 2.2934 (value 3) & $p<0.001$ \\
Ecological concern: Low/high & 2.357 (low) & 2.781 (high) & $p<0.001$ \\
Ecological behaviour: Low/high & 2.342 (low) & 2.778 (high) & $p<0.001$ \\
Innovativeness: Low/high & 2.351 (low) & 2.720 (high) & $p<0.001$ \\
\hline
\end{tabular}

For all six multi-group analyses, the model proved to be metrically invariant. Imposing across-group constraints on all item loadings only resulted in a minor or no drop in TLI, CFI and RMSEA [115]. Therefore, the multi-group analyses were carried out assuming an invariant measurement model. All multi-group models resulted in $\mathrm{chi}^{2} / \mathrm{df}<3$, RSMEA $<0.05$ and TLI and CFI $>0.88$. Subsequently, similar to Koller et al. [2], differences in standardized regression weights between groups were tested by means of t-tests. The results of these multi-group comparisons are shown in Table 7, in which standardized regression weights per group are shown, and significant effects and significant differences between groups are indicated.

A number of causal paths are similar across consumer segments. Emotions towards the electric car are in most models the most important predictor of usage intention. Emotions are most strongly affected by electric car compatibility followed by its lack of complexity. The attitude towards the electric car is the second most important driver of usage intention. The lack of complexity has the strongest influence on the attitude towards the electric car, followed by the relative advantage of the electric car and its compatibility. The subjective norm (peers and media) has a significant positive effect on usage intention. The perception of one's own ability to drive an electric car has no significant effect. External constraints and facilitators only play a marginal role in developing usage intention. Perceived relative advantage, compatibility and lack of complexity, and the media social norm all have a positive influence on the emotions towards the electric car. The perception of one's personal ability to drive an electric car has a significant positive influence on the emotions towards it. The effects of external constraints and facilitators on emotions are small and inconsistent. Car driving habits do not have an inhibiting effect on usage intention, although the former are positively influenced by visceral emotions towards current car driving and influenced negatively by reflective emotions towards car driving. Reflective emotions towards car driving have a direct effect on intention in some of the models. 
Table 7. Standardized regression weights per multi-group comparison model.

\begin{tabular}{|c|c|c|c|c|c|c|c|c|c|c|c|c|c|c|}
\hline \multirow[b]{2}{*}{ Constr. } & & \multirow[b]{2}{*}{ Constr. } & \multicolumn{2}{|c|}{$\begin{array}{c}\text { Environmental } \\
\text { Behaviour } \\
\end{array}$} & \multicolumn{2}{|c|}{$\begin{array}{c}\text { Environmental } \\
\text { Concern } \\
\end{array}$} & \multicolumn{2}{|c|}{ Innovativeness } & \multicolumn{2}{|c|}{ Value Clusters 1-2 } & \multicolumn{2}{|c|}{ Value Clusters 1-3 } & \multicolumn{2}{|c|}{ Value Clusters 2-3 } \\
\hline & & & Low & High & Low & High & Low & High & 1 & 2 & 1 & 3 & 2 & 3 \\
\hline \multirow[t]{16}{*}{ AI } & $\leftarrow$ & ATT & $0.206^{*}$ & $0.191 *$ & $0.191 *$ & $0.166^{*}$ & $0.017 *$ & $0.211 *$ & $0.281 *$ & 0.097 & $0.281 *$ & $0.165 *$ & $0.179 *$ & $0.165 *$ \\
\hline & $\leftarrow$ & SNP & 0.087 & 0.050 & 0.031 & $0.099 *$ & 0.060 & 0.058 & $0.151 *$ & 0.038 & $0.133 *$ & $-0.370 *$ & $0.088 *$ & $-0.374 *$ \\
\hline & $\leftarrow$ & SNM & 0.102 & $0.171 *$ & $0.180 *$ & $0.138 *$ & $0.279 *$ & 0.058 & 0.067 & 0.129 & 0.079 & $0.775 *$ & 0.095 & $0.780 *$ \\
\hline & $\leftarrow$ & PBCPA & 0.047 & -0.061 & 0.006 & -0.027 & 0.002 & -0.005 & 0.010 & -0.071 & 0.018 & 0.082 & -0.036 & 0.081 \\
\hline & $\leftarrow$ & ESC1 & 0.035 & 0.021 & 0.026 & 0.024 & 0.060 & 0.064 & 0.074 & -0.012 & 0.072 & 0.051 & 0.038 & 0.051 \\
\hline & $\leftarrow$ & $\mathrm{ESC} 2$ & 0.012 & $-0.093 *$ & -0.024 & -0.052 & 0.006 & 0.042 & -0.053 & -0.048 & 0.055 & -0.017 & -0.048 & -0.018 \\
\hline & $\leftarrow$ & ESC3 & 0.000 & -0.014 & -0.032 & 0.007 & 0.023 & $0.082 *$ & -0.003 & -0.021 & -0.003 & 0.018 & -0.018 & 0.018 \\
\hline & $\leftarrow$ & $\mathrm{ESC} 4$ & 0.061 & 0.051 & 0.053 & 0.060 & -0.007 & -0.007 & 0.005 & 0.064 & 0.004 & $0.120 *$ & 0.043 & $0.120 *$ \\
\hline & $\leftarrow$ & ESC5 & $0.074 *$ & 0.045 & 0.025 & $0.115 *$ & -0.036 & -0.036 & $0.103 *$ & $0.097 *$ & $0.107 *$ & -0.053 & 0.094 * & -0.054 \\
\hline & $\leftarrow$ & ESC6 & -0.033 & -0.034 & -0.060 & -0.016 & -0.023 & -0.016 & -0.015 & -0.076 & -0.015 & -0.029 & -0.037 & -0.028 \\
\hline & $\leftarrow$ & ESC7 & -0.025 & -0.022 & 0.013 & -0.045 & -0.048 & -0.041 & -0.063 & -0.009 & -0.065 & 0.036 & -0.035 & 0.037 \\
\hline & $\leftarrow$ & EEC & $0.424 *$ & $0.480 *$ & $0.418 *$ & $0.494 *$ & $0.369 *$ & $0.498 *$ & 0.356 * & $0.619 *$ & $0.339 *$ & 0.121 & 0.507 * & 0.121 \\
\hline & $\leftarrow$ & Habits & 0.075 & -0.046 & 0.000 & 0.028 & 0.018 & -0.010 & 0.035 & -0.005 & 0.046 & -0.011 & 0.015 & -0.008 \\
\hline & $\leftarrow$ & VISC & 0.014 & 0.073 & 0.084 & 0.003 & 0.049 & 0.038 & 0.045 & 0.039 & 0.042 & 0.035 & 0.038 & 0.033 \\
\hline & $\leftarrow$ & REFL & $0.165 *$ & 0.025 & 0.083 & 0.098 & 0.044 & 0.157 & $0.196 *$ & 0.048 & $0.234 *$ & 0.135 & $0.115 *$ & 0.128 \\
\hline & $\leftarrow$ & BEHAV & -0.005 & 0.047 & 0.051 & 0.001 & 0.024 & -0.001 & -0.001 & 0.003 & -0.018 & 0.026 & 0.011 & 0.032 \\
\hline \multirow[t]{10}{*}{ EEC } & $\leftarrow$ & RelAdv & 0.038 & $0.147 *$ & 0.038 & $0.118 *$ & $0.128 *$ & 0.050 & 0.084 & $0.135 *$ & 0.085 & -0.041 & $0.114 *$ & -0.040 \\
\hline & $\leftarrow$ & Comp & $0.569 *$ & $0.411 *$ & $0.431 *$ & $0.528 *$ & $0.539 *$ & $0.474 *$ & $0.424 *$ & $0.484 *$ & $0.423 *$ & $0.712 *$ & $0.452 *$ & 0.708 * \\
\hline & $\leftarrow$ & Compl & $0.217 *$ & $0.243 *$ & $0.266^{*}$ & $0.207 *$ & $0.160 *$ & $0.275 *$ & $0.278 *$ & $0.209 *$ & $0.275 *$ & $0.159 *$ & $0.232 *$ & $0.158 *$ \\
\hline & $\leftarrow$ & SNP & $-0.088 *$ & 0.028 & 0.013 & $-0.074 *$ & -0.042 & -0.016 & 0.001 & -0.021 & 0.000 & -0.024 & -0.023 & -0.028 \\
\hline & $\leftarrow$ & SNM & $0.153 *$ & $0.138 *$ & $0.185 *$ & $0.126 *$ & 0.111 & $0.156 *$ & $0.154 *$ & $0.119 *$ & $0.154 *$ & 0.021 & $0.154 *$ & 0.028 \\
\hline & $\leftarrow$ & PBCPA & $0.083 *$ & $0.115 *$ & $0.094 *$ & $0.122 *$ & $0.128 *$ & $0.094 *$ & 0.108 * & $0.102 *$ & $0.111 *$ & $0.134 *$ & $0.113 *$ & $0.133 *$ \\
\hline & $\leftarrow$ & $\mathrm{ESC} 1$ & $0.078 *$ & -0.008 & 0.056 & 0.034 & $-0.064 *$ & -0.007 & -0.021 & $0.103 *$ & -0.021 & 0.076 & 0.041 & 0.076 \\
\hline & $\leftarrow$ & $\mathrm{ESC} 2$ & -0.018 & -0.029 & -0.039 & -0.007 & 0.018 & 0.055 & 0.001 & -0.006 & 0.001 & -0.067 & -0.007 & -0.068 \\
\hline & $\leftarrow$ & ESC3 & -0.043 & -0.037 & $-0.066 *$ & -0.030 & 0.060 & -0.038 & -0.049 & -0.050 & -0.050 & -0.017 & $-0.055 *$ & -0.018 \\
\hline & $\leftarrow$ & ESC4 & -0.003 & 0.016 & -0.002 & 0.015 & -0.015 & $-0.059 *$ & -0.011 & -0.007 & -0.010 & 0.078 & -0.008 & 0.078 \\
\hline
\end{tabular}


Table 7. Cont.

\begin{tabular}{|c|c|c|c|c|c|c|c|c|c|c|c|c|c|c|}
\hline \multirow[b]{2}{*}{ Constr. } & \multirow{2}{*}{\multicolumn{2}{|c|}{ Constr. }} & \multicolumn{2}{|c|}{$\begin{array}{c}\text { Environmental } \\
\text { Behaviour } \\
\end{array}$} & \multicolumn{2}{|c|}{$\begin{array}{c}\text { Environmental } \\
\text { Concern } \\
\end{array}$} & \multicolumn{2}{|c|}{ Innovativeness } & \multicolumn{2}{|c|}{ Value Clusters 1-2 } & \multicolumn{2}{|c|}{ Value Clusters 1-3 } & \multicolumn{2}{|c|}{ Value Clusters 2-3 } \\
\hline & & & Low & High & Low & High & Low & High & Constr. & & Constr. & Low & High & Low \\
\hline & $\leftarrow$ & ESC5 & -0.032 & -0.032 & -0.008 & -0.043 & 0.004 & $-0.058 *$ & -0.016 & -0.031 & -0.016 & -0.079 & -0.022 & -0.080 \\
\hline & $\leftarrow$ & ESC6 & -0.010 & -0.044 & -0.031 & -0.029 & 0.051 & -0.025 & $-0.083 *$ & 0.000 & $-0.082 *$ & 0.054 & -0.045 & 0.054 \\
\hline & $\leftarrow$ & ESC7 & -0.004 & 0.033 & 0.021 & 0.008 & -0.032 & -0.004 & 0.034 & -0.039 & 0.036 & 0.041 & 0.002 & 0.040 \\
\hline \multirow[t]{3}{*}{ ATT } & $\leftarrow$ & COMPL & $0.335 *$ & $0.378 *$ & $0.465 *$ & $0.276 *$ & $0.335 *$ & $0.393 *$ & $0.379 *$ & $0.349 *$ & $0.380 *$ & $0.378 *$ & $0.361 *$ & $0.379 *$ \\
\hline & $\leftarrow$ & RELAD & $0.276 *$ & $0.284 *$ & $0.234 *$ & $0.294 *$ & $0.302 *$ & $0.249 *$ & $0.249 *$ & $0.344 *$ & $0.249 *$ & $0.234 *$ & $0.297 *$ & $0.234 *$ \\
\hline & $\leftarrow$ & COMP & $0.263 *$ & $0.237 *$ & $0.182 *$ & $0.305 *$ & $0.271 *$ & $0.218 *$ & $0.259 *$ & $0.190 *$ & $0.258 *$ & $0.272 *$ & $0.229 *$ & $0.272 *$ \\
\hline \multirow[t]{3}{*}{ HAB } & $\leftarrow$ & VISC & $0.294 *$ & $0.159 *$ & $0.230 *$ & $0.199 *$ & $0.133 *$ & $0.254 *$ & $0.345 *$ & 0.098 & $0.342 *$ & $0.224 *$ & $0.221 *$ & $0.229 *$ \\
\hline & $\leftarrow$ & REFL & $-0.289 *$ & $-0.199 *$ & $-0.202 *$ & $-0.306 *$ & $-0.268 *$ & $-0.273 *$ & $-0.285 *$ & $-0.175 *$ & $-0.308 *$ & $-0.340 *$ & $-0.240 *$ & $-0.318 *$ \\
\hline & $\leftarrow$ & BEHAV & 0.080 & $0.152 *$ & 0.047 & $0.195 *$ & $0.190 *$ & 0.063 & 0.086 & $0.128 *$ & 0.093 & 0.173 & $0.121 *$ & 0.156 \\
\hline
\end{tabular}

Cells are standardized regression weights, * indicates a significant effect at $p<0.05$; Bold indicates significant differences between groups at $p<0.05$. 
Looking at the value clusters, the disconnected nonconformist contrasts sharply with the other two personal value groups. Contrary to the positive effect in the other two groups, peers have a strongly negative effect on nonconformists' usage intention, and media have a much stronger positive effect on their intentions than in the other two value groups. Probably because of their disconnectedness, they seems to be "demotivated" by their peers to adopt the electric car. Apparently, they have a strong perception of their own ability to collect the information they need, and would not let themselves be influenced by others. Contrary to the other two groups, they are significantly driven by the idea that the electric car will give them the opportunity to drive long distances, they are not concerned about the budgetary consequences of buying an electric car, and most remarkably, they are neither driven by emotions towards the electric car nor by (reflective) emotions towards car driving.

The motivational determinants of usage intention are very similar across more or less environmentally concerned individuals. The environmentally concerned seem to be driven more by their reflective emotions about car driving, the perception of relative advantage and less by concerns about the complexity of the car. This may reflect the fact that they have thought about it more than environmentally less concerned individuals, and they will not be stopped so easily by complexity concerns.

The motivational determinants of respondents behaving more or less environmentally-friendly are also very similar, although there are some differences. Environmentally-friendly behaving people take media and relative advantage more into account, they seem to worry more about charging the battery and less about entering the city with traditional cars, and take their reflective emotions towards car driving less into account. Maybe these differences are the result of being more interested in and better informed by the media, as a result of their generally more environmentally friendly behaviour.

Reflective emotions towards current car driving significantly determine the usage intention of the innovative group. Less innovative people are more driven by what appears in the media about the electric car. A sufficient budget and a long driving distance only motivate the innovative people. Relative advantage only determines these emotions for the less innovative people. Only the highly innovative group is emotionally influenced by the media. The emotions towards the electric car of the less innovative people are driven by having sufficient budget to buy one, being able to drive for a long distance, and no longer being allowed to charge the car for free at home. More innovative people get more emotional about the electric car due to the fact that the current car will no longer be allowed in the centre of the city, it might not be possible for everyone to charge it at home, and a good maintenance structure. Behavioural emotions only reinforce the habits of the less innovative people.

\section{Discussion}

The key purpose of the present study was, for the first time, to test a comprehensive model in which, besides cognitive motivations of innovation adoption, also the relative importance of the emotional response towards the electric car, as well as the role of car driving habits and their emotional antecedents were considered.

Adding emotional components to the TPB appears to be highly relevant. Emotions towards the electric car are the most important factor that drives electric car usage intention. This is in line with earlier research, indicating that people make pro-environmental choices based on feelings of excitement and pleasure $[2,12,22,116,117]$. Most effects of cognitive considerations, such as perceived compatibility, 
perceived lack of complexity, the subjective norm incited by the media and the perception of one's own ability to use the car, on usage intention are mediated by the emotions towards the electric car. This result illustrates that rational, cognitive factors affect the usage intention of a relatively high involvement, technologically innovative and environmentally-friendly product mainly through the affective reaction they evoke. This confirms theories such as the Affect Infusion Model [52] that even substantive processing emotions are important, and that cognitive considerations influence behavioural intention through their effect on felt emotions. The attitude towards the electric car is also very important and is, in turn, strongly determined by the lack of complexity, but also by the compatibility and the relative advantage of the electric car. This confirms the literature on the DTPB [35].

The role of the subjective norm as a motivational determinant in adopting the electric car is also confirmed. The influence of media is of greater importance than the influence of peers in this early adoption stage of the electric car. The media apparently provide an anchoring point for acceptable norms with respect to cars. Moreover, media also affect the emotions towards the electric car. The influence by peers is not yet a big issue. This may be explained by the fact that, in this stage, one is not yet exposed to electric cars in the streets. On the contrary, all peers are still driving a car with a combustion engine. Consequently, the electric car cannot yet contribute to one's self-image [118].

Car driving emotions are experienced in three main dimensions: Visceral, behavioural and reflective [73]. Especially reflective emotions are significant drivers of electric car usage intention. This is in line with earlier research on product category related emotions $[8,16]$. Behavioural and especially visceral emotions have a positive effect on driving habits. Reflective emotions (based on cognitive considerations about the negative consequences of car driving) have a negative effect on habits. This is in line with our expectations of the reinforcement of habits through positive emotions with the product. However, these car driving habits do not have an effect on electric car usage intention. The electric car may not be perceived as a trigger for changing the car using habits one has. It does not change the routinized behaviour of choosing between taking the car automatically or considering another travel mode choice. Moreover, people seem to perceive driving an electric car as something that is not very different from driving a car with a combustion engine. Nevertheless, reflective car driving emotions have a significant, though relatively small, direct positive effect on electric car usage intention.

Contrary to expectations, external constraints and facilitators are less relevant. The electric car may be at such an early stage of introduction that many people do not realise the consequences of its use due to a lack of information. This result is surprising because factors such as "range anxiety" (the perception that, without charging possibility, electric cars have a limited range) or battery charging issues dominate the debate on the success of electric cars. However, these results are partly in line with the findings of Hensley et al. [119] in that a lack of information or awareness about constraints and facilitators may reduce their impact on usage intention.

In general, the result confirms the relevance and importance of integrating emotions towards car driving and electric cars in the Decomposed Theory of Planned Behaviour framework, which is in line with the conclusions from earlier research as to the pivotal role of feelings in this decision making process $[6,10,13,52,73,120,121]$.

Additionally, the moderating role of various consumer characteristics on intention formation were explored. Although people that are highly environmentally concerned already demonstrate more environmentally-conscious behaviour, and innovative individuals pronounce stronger intentions to use 
the electric car, individuals differing in environmentally friendly behaviour, environmental concern and innovativeness do not show substantial differences in motivational structure. However, in line with earlier research on pro-environmental behaviour [68,79,80], personal values seem a useful categorization in the quest for early adopter segments of the electric car. Adventurous hedonists and powerless benevolents pronounce the same intention to use the electric car, while the disconnected nonconformists are more resistant. The disconnected nonconformists is the most special group. They have the lowest intention to use the electric car and seem hard to convince. These are the only people that are not significantly driven by emotions. They are motivated by the freedom to drive long distances and have a strong perception of their own ability to collect the information they need, and will not let themselves be influenced by others. More rational arguments to stimulate their attitude will be more convincing for these value type. The opinion of their peers has a negative effect on them. Media is more helpful to motivate them.

Our study has some limitations that provide opportunities for further research. First of all, triability and observability were not included in the model, because of the unavailability and lack of visibility of electric cars at the time of the study. Consequently, the only thing respondents could have answered was that the electric cars could neither be observed nor tried. However, modelling the motivational process in later stages of the diffusion of electric cars should definitely include these two drivers of innovation adoption. Measuring anticipated emotions towards a new product is indeed not an easy task for consumers. Future research could use more sophisticated visual and verbal stimuli of electric cars to make the proposition more concrete and to enable consumers to connect to the idea of an electric car in a more realistic way. Research into "ethical" consumer behaviour always carries the risk of socially desirable answers. Although we do not have indications of social desirability in the current study, future research could explicitly test this. In surveys in which various related constructs are measured in the same sample of respondents, common method bias could affect the results. Future research could explicitly test common method bias.

\section{Implications}

The study contributes to practice as it provides designers, marketers and public institutions with insights to fine-tune their persuasive efforts to convince different market segments and specifically possible early adopters. Appealing to positive emotions is crucial for new product development and the acceptance of innovations [2]. Product designers and marketers should develop and position electric cars in such a way that they lead to positive attitudes, but much more importantly, that they evoke positive emotional responses. Emphasizing emotional elements in the design and advertising of electric cars is of crucial importance. Electric car design, marketing and public awareness campaigns should strive to evoke positive visceral and reflective emotions about driving them, and take away the negative effects of behavioural emotions by demonstrating to people that driving electric cars does not limit their positive behavioural car driving sensations.

Concerns about the complexity of the electric cars seem important in that they have a strong impact on attitudes and emotional reactions. Therefore, marketing campaigns should emphasize that using an electric car is simple. Product design should be made very intuitive. In this stage of the pre-adoption 
process, before hoping to create buzz and worth-of-mouth, mass media campaigns should be considered as, at this point, they have a stronger impact on intention formation than the peer-to-peer subjective norm.

Breaking through habits is considered important for achieving sustainability. However, habits do not seem to be a significant constraint for electric car usage intention. This may be due to the possible perception of the electric car as being in line with current car driving habits. This offers an angle for marketers and public policy, namely stressing the fact that driving an electric car is not basically different from using a traditional one, and that consumers do not have to change their habits when buying an electric model. Breaking habits should thus not be stressed in campaigns promoting electric car use. Reflective emotions towards car driving have a positive effect on electric car usage intention. Consequently, campaigns and electric car design appealing to reflective emotional experiences may be a good idea.

The results also imply the importance of information that the media spread about the electric car. Media messages should in the first place stress the positive emotions one could expect from driving a more environmentally friendly car. However, also its simplicity, its compatibility with what one is used to and the advantages compared to the car with a combustion engine can be part of an information campaign. On the other hand, the influence of peers on the adoption process is limited. Although Griskevicius et al.'s [43] findings suggest that status considerations can be used to promote pro-environmental behavior, we do not find support for this peer-related effect.

In terms of early adoption segments, the best chance to get the adoption process started is to persuade innovative individuals who are environmentally concerned, who already act in a more environmentally friendly way and stick to values such as adventure, hedonism, and benevolence. Especially, positive emotions and attitudes towards the electric car and its simplicity in use should be stressed, and reflective emotions towards car driving should be triggered.

\section{Conclusions}

Extending the Decomposed Theory of Planned Behaviour with emotional adoption motivations appears to be highly relevant. Overall, the results confirm that emotions are the most important driver of electric car usage intention, followed by attitude, except for people not hanging on to values of caring, adventure and tradition, but that consider power and non-conformism as important values (disconnected nonconformists). Attitude, in turn, is determined by lack of complexity, compatibility and relative advantage of the electric car. Reflective emotions towards current car driving are for most segments significant drivers of usage intention. Overall, the motivational power of external constraints and facilitators is limited. The role of media seems to be of more importance than the influence peers exert on the adoption process. Habits seem irrelevant in predicting electric car usage intention. Most of the cognitive motivations to use the electric car are mediated by the emotions towards the electric car. Apparently, under high involvement and substantive processing, emotions play an important role.

The only category of people that are not significantly driven by emotions are people that value power and non-conformism (labelled as disconnected nonconformists). On this behalf, they are in strong contrast with the powerless benevolents whose main driver of usage intention are the emotions towards the electric car. Although people that are highly environmentally concerned pronounce a stronger intention to use the electric car, the process underlying this intention does not differ from those 
pronouncing less environmental concern. The same goes for individuals that already demonstrate more or less environmental behaviour as well as more or less innovative individuals.

\section{Author Contributions}

The authors have each contributed equally to the research and the manuscript.

\section{Conflicts of Interest}

The authors declare no conflict of interest.

\section{References}

1. Smith, R.A. Enabling technologies for demand management. Energy Policy 2008, 36, 4444-4448.

2. Koller, M.; Floh, A.; Zauner, A. Further Insights into perceived value and consumer loyalty: A "green" perspective. Psychol. Mark. 2011, 28, 1154-1176.

3. Feitelson, E.; Salomon, I. The implications of differential network flexibility for spatial structures. Transp. Res. A 2000, 34, 459-479.

4. Verhoef, E.; van Wee, B.; Steg, L.; Bliemer, M. Pricing in Road Transport: A Multi-Disciplinary Perspective; Edgar Elgar: Cheltenham, UK, 2008.

5. Calantone, R.J.; Chan, K.; Cui, A.S. Decomposing product innovativeness and its effects on new product success. J. Prod. Innovat. Manag. 2006, 23, 408-421.

6. Perlusz, S. Emotions and Technology Acceptance: Development and Validation of a Technology Affect Scale. Available online: http://jgxy.usx.edu.cn/DAOM/046_StefanoPerlusz.pdf (accessed on 16 May 2015).

7. Bagozzi, R.P.; Gopinath, M.; Nyer, P.U. The role of emotions in marketing, J. Acad. Mark. Sci. 1999, 27, 184-206.

8. Richins, M.L. Measuring emotions in the consumption experience. J. Consum. Res. 1997, 24, $127-146$.

9. Kim, H.W.; Chan, H.C.; Chan, Y.P. A balanced thinking-feelings model of information systems continuance. Int. J. Hum. Comput. Stud. 2007, 65, 511-525.

10. Pham, M.T. Representativeness, relevance, and the use of feelings in decision making. J. Consum. Res. 1998, 25, 144-159.

11. Sheller, M. Automotive emotions: Feeling the car. Theory C. Soc. 2004, 21, 221-242.

12. Steg, L.; Vlek, C.; Slotegraaf, G. Instrumental-reasoned and symbolic-affective motives for using a motor car. Transp. Res. F 2001, 4, 151-169.

13. Chaudhuri, A.; Aboulnasr, K.; Ligas, M. Emotional responses on initial exposure to a hedonic or utilitarian description of a radical innovation. J. Mark. Theory Pract. 2010, 18, 339-359.

14. Shiv, B.; Fedorikhin, A. Heart and mind in conflict: The interplay of affect and cognition in consumer decision making. J. Consum. Res. 1999, 26, 278-292.

15. Gatersleben, B.; Appleton, K. Contemplating cycling to work: Attitudes and perceptions in different stages of change. Transp. Res. A 2007, 41, 302-312.

16. Gärling, A.; ThØgersen, J. Marketing of electric vehicles. Bus. Strategy Environ. 2001, 10, 53-65. 
17. Aarts, H.; Verplanken, B.; van Knippenberg, A. Habit and information use in travel mode choices. Acta Psychol. 1997, 96, 1-14.

18. Gärling, T.; Karlsson, N.; Romanus, J.; Selart, M. Influences of the past on choices of the future. In Decision Making: Cognitive Models and Explanations; Raynard, R., Crozier, W.R., Svenson, O., Eds.; Routledge: London, UK, 1997; pp. 167-188.

19. Norman, P.; Smith, L. The theory of planned behaviour and exercise: An investigation into the role of prior behaviour, behavioural intentions and attitude variability. Eur. J. Soc. Psychol. 1995, 25, 403-415.

20. Klöckner, C.A.; Matthies, E. How habits interfere with norm directed behaviour: A normative decision-making model for travel mode choice. J. Environ. Psychol. 2004, 24, 319-417.

21. Tengstrom, R. The Use of the Automobile: Its Implications for Man, Society and the Environment; Swedish Transport Research Board, TFB Reprot 1992:14; Swedish Transport Research Board: Stockholm, Swedish, 1992.

22. Sandqvist, K. The Appeal of Automobiles-Human Desires and the Proliferation of Cars; KBF Report; The Swedish Transport and Communication Research Board: Stockholm, Sweden, 1997.

23. Urban, G.L.; Hauser, J.R.; Urban, G.L. Design and Marketing of New Products; Prentice Hall: Englewood Cliffs, NJ, USA, 1993.

24. Taylor, S.; Todd, P. Understanding information technology usage: A test of competing models. Inform. Syst. Res. 1995, 6, 144-176.

25. Fishbein, M.; Ajzen, I. Belief, Attitude, Intention and Behaviour; Addison-Wesley: Reading, MA, USA, 1975.

26. Pavlou, P.A.; Fygenson, M. Understanding and predicting electronic commerce adoption: An extension of the theory of planned behaviour. MIS Q. 2006, 30, 115-143.

27. Stern, P.C.; Dietz, T.; Abel, T.; Guagnano, G.A.; Kalof, L. A value belief norm theory of support for social movements: The case of environmentalism. Hum. Ecol. Rev. 1999, 6, 81-97.

28. Thøgersen, J. How may consumer policy empower consumers for sustainable lifestyles? J. Consum. Policy 2005, 28, 143-178.

29. Van Raaij, W.F. Stages of behavioural change: Motivation, ability and opportunity. In Marketing for Sustainability; towards Transactional Policy-Making; Bartels, G., Nelissen, W., Eds.; IOS Press: Amsterdam, the Netherlands, 2002; pp. 321-333.

30. Bamberg, S.; Smith, P. Regulating transport: Behavioural changes in the field. J. Consum. Pol. 1999, 22, 479-509.

31. Kaiser, F.G.; Woefling, S.; Fuhrer, U. Environmental attitude and ecological behaviour. J. Environ. Psychol. 1999, 19, 1-19.

32. Cheung, S.F.; Chang, D.K.-S.; Wong, Z.S.-Y. Reexamining the theory of planned behaviour in understanding wastepaper recycling. Environ. Behav. 1999, 31, 587-612.

33. Lam, S.P. Predicting intentions to conserve water from the theory of planned behaviour, perceived moral obligation, and perceived water right. J. Appl. Soc. Psychol. 1999, 29, 1058-1071.

34. Rogers, E.M. Diffusion of Innovations; Free Press: New York, NY, USA, 1995.

35. Moore, D.M.; Benbasat, I. Development of an instrument to measure the perceptions of adopting information technology innovation. Inf. Syst. Res. 1991, 2,192-222. 
36. Davis, F.D. Perceived usefulness, perceived ease of use, and user acceptance of information technology. MIS Q. 1989, 13, 319-339.

37. King, W.R.; He, J. A meta-analysis of technology acceptance model. Inf. Manag. 2006, 43, 740-755.

38. Schepers, J.; Wetzels, M. A meta-analysis of the technology acceptance model: Investigating subjective norm and moderation effects. Inf. Manag. 2007, 44, 90-103.

39. Davis, F.D.; Bagozzi, R.P.; Warshaw, P.R. Extrinsic and intrinsic motivation to use computers in the workplace. J. Appl. Soc. Psychol. 1992, 22, 111-1132.

40. Plouffe, C.R.; Hulland, J.S.; Vandenbosch, M. Research Report: Richness versus Parsimony in modelling Technology Adoption Decisions-Understanding Merchant Adoption of a Smart Card-based Payment system. Inform. Syst. Res. 2001, 12, 208-222.

41. Hung, S.Y.; Chang, C.M. User acceptance of WAP services: Test of competing theories. Comput. Stand. Interface 2005, 27, 359-370.

42. Tan, M.; Teo, T.S. Factors influencing the adoption of Internet banking. J. Assoc. Inf. Sys. 2000, 1, Article 5.

43. Griskevicius, V.; Tybur, J.M.; van den Bergh, B. Going green to be seen: Status, reputation, and conspicuous conservation. J. Pers. Soc. Psychol. 2010, 98, 392-404.

44. Ajzen, I. The theory of planned behaviour. Organ. Behav. Hum. Decis. Processes 1991, 50, 179-221.

45. Trafimow, D.; Sheeran, P.; Conner, M.; Finlay, K.A. Evidence that perceived behavioural control is a multidimensional construct: Perceived control and perceived difficulty. Br. J. Soc. Psychol. 2002, 41, 101-121.

46. Bandura, A. Social Foundations of Thought and Action; Prentice Hall: Englewood Cliffs, NJ, USA, 1986.

47. Triandis, H.C. Interpersonal Behavior; Brook/Cole: Monetery, CA, USA, 1977.

48. Venkatesh, V.; Morris, M.G.; Davis, G.B.; Davis, F.D. User acceptance of information technology: Toward a unified view. MIS Q. 2003, 27, 425-478.

49. Avlonitis, G.J.; Panagopoulos, N.G. Antecedents and consequences of CRM Technology Acceptance in Sales Forces. Ind. Market. Manag. 2005, 34, 355-368.

50. Frijda, N.H. Varieties of affect: Emotions and episodes, moods, and sentiments. In The Nature of Emotions: Fundamental Questions; Ekman, P., Davison, R., Eds.; Oxford University Press: New York, NY, USA, 1994; pp. 197-202.

51. Petty, R.E.; Cacioppo, J.T. Communication and Persuasion: Central and Peripheral Routes to Attitude Change; Springer-Verlag: New York, NY, USA, 1986.

52. Forgas, J.P. Mood and judgment: The affect infusion model (AIM). Psychol. Bull. 1995, 117, 39-66.

53. Pham, M.T. The logic of feeling. J. Consum. Psychol. 2004, 14, 360-369.

54. Parker, D.; Manstead, A.S.R.; Stradling, S.G. Extending the theory of planned behaviour: The role of personal norm. Br. J. Soc. Psychol. 1995, 34, 127-137.

55. Richard, R.; van der Pligt, J.; de Vries, N. Anticipated affective reactions and prevention of AIDS. Br. J. Soc. Psychol. 1995, 34, 9-21.

56. Hsu, C.L.; Lu, H.P.; Hsu, H.H. Adoption of the mobile Internet: An empirical study of multimedia message service (MMS). Omega 2007, 35, 715-726.

57. Wang, X. The role of anticipated negative emotions and past behaviour in individuals' physical activity intentions and behaviours. Psychol. Sport Exerc. 2011, 12, 300-305. 
58. Bae, H.S. Entertainment-education and recruitment of cornea donors: The role of emotion and issue involvement. J. Health Commun. 2008, 13, 20-36.

59. Hynie, M.; MacDonald, T.K.; Marques, S. Self-conscious emotions and self-regulation in the promotion of condom use. Pers. Soc. Psychol. B 2006, 32, 1072-1084.

60. Perugini, M.; Bagozzi, R.P. The role of desires and anticipated emotions in goal-directed behaviours/Broadening and deepening the theory of planned behaviour. Br. J. Soc. Psychol. 2001, 40, 79-98.

61. Duran, M.; Alzate, M.; Lopez, W.; Sabucedo, M. Emotions and pro-environmental behavior. Rev. Lat. Am. Psicol. 2011, 39, 287-296.

62. Wood, S.L.; Moreau, C.P. From fear to loathing? How emotion influences the evaluation and early use of innovations. J. Mark. 2006, 70, 44-57.

63. Kwortnik, R.J.; Ross, W.T. The role of positive emotions in experiential decisions. Int. J. Res. Mark. 2007, 24, 324-335.

64. Bagozzi, R.P. The legacy of the technology acceptance model and a proposal for a paradigm shift. $J$. Assoc. Inf. Sys. 2007, 8, 244-254.Verplanken, B.; Aarts, H.; van Knippenberg, A. Habit, information acquisition and the process of making travel mode choices. Eur. J. Soc. Psychol. 1997, 27, 539-560.

66. Wood, W.; Tam, L.; Witt, M.G. Changing circumstances, distrupting habits. J. Pers. Soc. Psychol. 2005, 88, 918-933.

67. Wood, W.; Neal, D.T. A new look at habits and the habit-goal interface. Psychol. Rev. 2007, $114,843$.

68. Gärling, T.; Axhausen, K.W. Introduction: Habitual travel choice. Transportation 2003, 30, 1-11.

69. Verplanken, B.; Aarts, H.; van Knippenberg, A.; Moonen, A. Habit versus planned behaviour: A field experiment. Br. J. Soc. Psychol. 1998, 37, 111-128.

70. Verplanken, B.; Aarts, H.; van Knippenberg, A.; van Knippenberg, C. Attitude versus general habit: Antecedents of travel mode choice. J. Appl. Soc. Psychol. 1994, 24, 285-300.

71. Gardner, B. Modelling motivation and habit in stable travel mode contexts. Transport. Res. F 2009, $12,68-76$.

72. Thøgersen, J.; Olander, F. The dynamic interaction of personal norms and environment friendly buying behavior: A panel study. J. Appl. Soc. Psychol. 2006, 36, 1758-1780.

73. Norman, D.A. Emotional Design; Basic Books: New York, NY, USA, 2004.

74. Kilbourne, W.E.; Beckmann, S.C. Review and critical assessment of research on marketing and the environment. J. Mark. Manag. 1998, 14, 513-532.

75. Jansson, J. Consumer eco-innovation adoption: Assessing attitudinal factors and perceived product characteristics. Bus. Strategy Environ. 2011, 20, 192-210.

76. Schwartz, S.H. Universals in the content and structure of values: Theoretical advances and empirical tests in 20 countries. In Advances in Experimental Social Psychology; Zanna, M., Ed.; Academic Press: Orlando, FL, USA, 1992; pp. 1-65.

77. Thøgersen, J. Recycling and morality. A critical review of the literature. Environ. Behav. 1996, 28, $536-558$.

78. Schultz, P.W.; Zelezny, L. Values as predictors of environmental attitudes: Evidence for consistency across 14 countries. J. Environ. Psychol. 1999, 19, 255-265. 
79. Leonidou, L.C.; Leonidou, C.N.; Kvasova, O. Antecedents and outcomes of consumer environmentally friendly attitudes and behaviour. J. Mark. Manag. 2010, 26, 1319-1344.

80. Kilbourne, W.E.; Pickett, G. How materialism affects environmental beliefs, concerns, and environmental responsible behaviour. J. Bus. Res. 2008, 61, 885-893.

81. Chua, W.L.; Lee, A.; Sadeque, S. Why do people buy hybrid cars? In Proceedings of the Social Marketing Forum, Churchland, Australia, 13 August 2010; pp. 1-13.

82. Fransson, N.; Gärling, T. Environmental concern: Conceptual definitions, measurement methods and research findings. J. Environ. Psychol. 1999, 19, 369-282.

83. Eagly, A.H.; Chaiken, S. Attitude structure and function. In Handbook of Social Psychology; Gilbert, D.T., Fiske, S.T., Lindzey, G., Eds; McGraw-Hill: Englewood Cliffs, NJ, USA, 1998; pp. 269-322.

84. Schultz, P.W. The structure of environmental concern: Concern for self, other people, and the biosphere. J. Environ. Psychol. 2001, 21, 327-339.

85. Bamberg, S. How does environmental concern influence specific environmentally related behaviors? A new answer to an old question. J. Environ. Psychol. 2003, 23, 21-32.

86. Bamberg, S.; Möser, G. Twenty years after Hines, Hungerford and Tomera: A new meta-analysis of psycho-social determinants of pro-environmental behaviour. J. Environ. Psychol. 2007, 27, 14-25.

87. Oliver, J.D.; Rosen, D.E. Applying the environmental propensity framework: A segmented approach to hybrid electric vehicle marketing strategies. J. Mark. Theory Pract. 2010, 18, 377-393.

88. Heffner, R.R.; Kurani, K.S.; Turrentine, T.S. Symbolism in California's early market for hybrid electric vehicles. Transport. Res. D 2007, 12, 396-413.

89. Gallagher, K.S.; Muehlegger, E. Giving green to get green? Incentives and consumer adoption of hybrid vehicle technology. J. Environ. Econ. Manag. 2011, 61, 1-15.

90. Nilsson, M.; Kuller, R. Travel behavior and environmental concern. Transp. Res. D 2000, 5, 211-234.

91. Hines, J.M.; Hungerford, H.R.; Tomera, A.N. Analysis and synthesis of research on responsible environmental behavior: A meta-analysis. J. Environ. Educ. 1987, 18, 1-8.

92. Browne, J.D.; Wahlers, R.G. The environmentally concerned consumer: An exploratory study. J. Mark. Theory Pract. 1998, 6, 39-47.

93. Ginsberg, J.M.; Bloom, P.N. Choosing the right green marketing strategy. MIT Sloan Manag. Rev. 2004, 46, 79-84.

94. Minton, A.P.; Rose, R.L. The effects of environmental concern on environmentally friendly consumer behavior: An exploratory study. J. Bus. Res. 1997, 40, 37-48.

95. Thøgersen, J. Spill-over processes in the development of a sustainable consumption pattern. J. Econ. Psychol. 1999, 20, 53-81.

96. Steenkamp, J.B.E.M.; ter Hofstede, F.; Wedel, M. A cross-national investigation into the individual and national cultural antecedents of consumer innovativeness. J. Mark. 1999, 55-69.

97. Egbue, O.; Long, S. Barriers to widespread adoption of electric vehicles: An analysis of consumer attitudes and perceptions. Energy Policy 2012, 48, 717-729.

98. Edison, S.W.; Geissler, G.L. Measuring attitudes towards general technology: Antecedents, hypotheses and scale development. J. Target. Meas. Anal. Mark. 2003, 12, 137-156. 
99. Sovacool, B.K.; Hirsh, R.F. Beyond batteries: An examination of the benefits and barriers to plug-in hybrid electric vehicles (PHEVs) and a vehicle-to-grid (V2G) transition. Energy Policy 2009, 37, 1095-1103.

100. Laurans, G.F.G.; Desmet, P.M.A. Introducing PREMO2: New directions for the non-verbal measurement of emotion in design. In Proceedings of the 8th International Conference on Design and Emotion, London, UK, 11-14 September 2012.

101. Cauberghe, V.; de Pelsmacker, P. Adoption intentions toward interactive digital television, among advertising professionals. J. Interact. Advert. 2011, 11, 45-59.

102. Verplanken, B.; Orbell, S. Reflections on past behavior: A self-report index of habit strength. J. Appl. Soc. Psychol. 2003, 33, 1313-1330.

103. Haustein, S.; Klöckner, C.A.; Blöbaum, A. Car use of Young adults: The role of travel socialization. Transport. Res. F 2009. 12, 168-178.

104. Erikson, L.; Garvill, J.; Nordlund, A.M. Interrupting habitual car use: The importance of car habit strength and moral motivation for personal car use reduction. Transp. Res. F 2008, 11, 10-23.

105. Anderson, J.C.; Gerbing, D.W. Structural Equation Modeling in practice: A review and recommended two-step approach. Psychol. Bull. 1988, 103, 411-423.

106. Golob, T.F. Structural Equation Modeling for travel behavior research. Transp. Res. B Methodol. 2003, 37, 1-25.

107. Bagozzi, R.P.; Yi, Y. On the evaluation of structural equation models. J. Acad. Mark. Sci. 1988, 16, 74-94.

108. Hansla, A.; Gamble, A.; Juliusson, A.; Gärling, T. The relationships between awareness of consequences, environmental concern, and value orientations. J. Environ. Psychol 2008, 28, 1-9.

109. Dunlap, R.E. The new environmental paradigm scale: From marginality to worldwide use. J. Environ. Educ. 2008, 40, 3-18.

110. Whitmarsh, L. Behavioural responses to climate change: Asymmetry of intentions and impacts. J. Environ. Psychol. 2009, 29, 13-23.

111. Roehrich, G. Consumer innovativeness: Concepts and measurements. J. Bus. Res. 2004, 57, 671-677.

112. Vankatramen, M.P.; Price, L.L. Differentiating between cognitive and sensory innovativeness. Concepts, measurement and implications. J. Bus. Res. 1990. 20, 293-315.

113. Hair, J.F.; Anderson, R.E.; Tatham, R.L.; William, C.; Black, M. Multivariate Data Analysis; Prentice Hall: Mahwah, NJ, USA, 1998.

114. Sobel, M.E. Asymptotic confidence intervals for indirect effects in structural equation models. In Sociological Methodology; Einhardt, S., Ed.; American Sociological Association: Washington, DC, USA, 1982; pp. 290-312.

115. Little, T.D.; Preacher, K.J.; Selig, J.P.; Card, N.A. New developments in latent variable panel analyses of longitudinal data. Int. J. Behav. Dev. 2007, 31, 357-365.

116. Ellaway, A.; Mcintyre, S.; Hiscock, R.; Keans, A. In the driving seat: Psychological benefits from private motor vehicle transport compared to public transport. Transp. Res. F 2003, 6, 217-231.

117. Stradling, S.G.; Meadows, M.L.; Beatty, S. Factors Affecting Car Use Choices; Transport Research Institute: Edinburgh, Scotland, 1999. 
118. Childers, T.L.; Rao, A.R. The influence of familial and peer-based reference groups on consumer decisions. J. Consum. Res. 1992, 19, 198-211.

119. Hensley, R.; Knupfer, S.M.; Krieger, A. The fast lane to the adoption of electric cars. McKinsey $Q$. 2011, $1,10-14$.

120. Hsiao, K.A.; Chen, L.L. Fundamental dimensions of affective responses to product shapes. Int. J. Ind. Ergonom. 2006, 36, 553-564.

121. Jordan, P.W. Pleasure with products: Human factors for body, mind and soul. In Human Factors in Product Design: Current Practice and Future Trends; Green, W.S., Jordan, P.W., Eds; Taylor and Francis: London, UK, 1999; pp. 206-217.

(C) 2015 by the authors; licensee MDPI, Basel, Switzerland. This article is an open access article distributed under the terms and conditions of the Creative Commons Attribution license (http://creativecommons.org/licenses/by/4.0/). 